\title{
Medical management of epileptic seizures: challenges and solutions
}

This article was published in the following Dove Press journal:

Neuropsychiatric Disease and Treatment

24 February 2016

Number of times this article has been viewed

\section{Anand K Sarma' \\ Nabil Khandker ${ }^{l}$ \\ Lisa Kurczewski \\ Gretchen M Brophy² \\ 'Department of Neurology, ${ }^{2}$ Departments of Pharmacotherapy \& Outcomes Science and Neurosurgery, Virginia Commonwealth University, \\ Richmond, VA, USA}

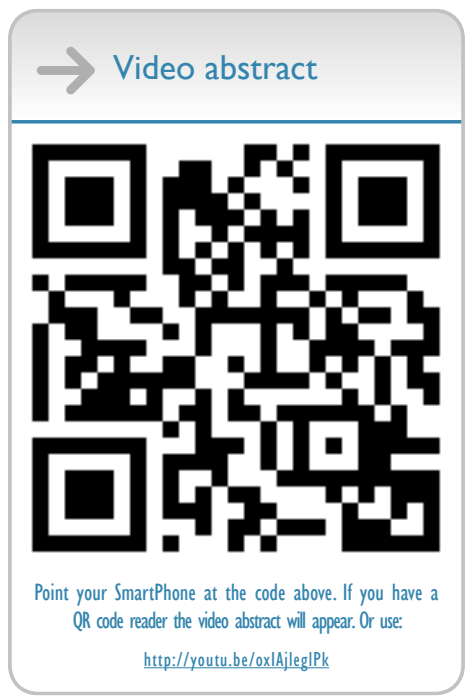

Correspondence: Gretchen M Brophy Departments of Pharmacotherapy \& Outcomes Science and Neurosurgery, Virginia Commonwealth University, 410 North 12th Street, Richmond, VA 23298-0533, USA

Tel + I 804828 I20I

Fax +l 8048280343

Email gbrophy@vcu.edu
Abstract: Epilepsy is one of the most common neurologic illnesses. This condition afflicts 2.9 million adults and children in the US, leading to an economic impact amounting to $\$ 15.5$ billion. Despite the significant burden epilepsy places on the population, it is not very well understood. As this understanding continues to evolve, it is important for clinicians to stay up to date with the latest advances to provide the best care for patients. In the last 20 years, the US Food and Drug Administration has approved 15 new antiepileptic drugs (AEDs), with many more currently in development. Other advances have been achieved in terms of diagnostic modalities like electroencephalography technology, treatment devices like vagal nerve and deep-brain stimulators, novel alternate routes of drug administration, and improvement in surgical techniques. Specific patient populations, such as the pregnant, elderly, those with HIV/AIDS, and those with psychiatric illness, present their own unique challenges, with AED side effects, drug interactions, and medical-psychiatric comorbidities adding to the conundrum. The purpose of this article is to review the latest literature guiding the management of acute epileptic seizures, focusing on the current challenges across different practice settings, and it discusses studies in various patient populations, including the pregnant, geriatric, those with HIV/AIDS, comatose, psychiatric, and "pseudoseizure" patients, and offers possible evidence-based solutions or the expert opinion of the authors. Also included is information on newer AEDs, routes of administration, and significant AED-related drug-interaction tables. This review has tried to address only some of these issues that any practitioner who deals with the acute management of seizures may encounter. The document also highlights the numerous avenues for new research that would help practitioners optimize epilepsy management.

Keywords: epilepsy, pregnancy, HIV/AIDS, psychiatric, pseudoseizures, management

\section{Introduction}

Epilepsy is one of the most common neurologic illnesses. This condition afflicts 2.9 million adults and children in the US, leading to an economic impact amounting to $\$ 15.5$ billion. ${ }^{1}$ Despite the significant burden epilepsy places on the population, it is not very well understood. Diagnosis and management of epilepsy is an active area of research. As understanding of this disease continues to evolve, it is important for clinicians to stay up to date with the latest advances to provide the best care for patients. In the last 20 years, the US Food and Drug Administration (FDA) has approved 15 new antiepileptic drugs (AEDs), with many more currently in development. ${ }^{2}$ Other advances have been achieved in terms of surgical management, electroencephalography (EEG) technology, and alternate routes of administration. Managing epilepsy patients can be challenging, due to the complex nature of the disease. AED side effects, drug interactions, and medical/psychiatric comorbidities are the typical scenarios that add to the conundrum. Specific patient populations, such as the pregnant, elderly, and those with HIV/AIDS and psychiatric illness, present their own unique challenges. 
The purpose of this article is to review the latest literature guiding the management of acute epileptic seizures. Specific status epilepticus (SE)-management strategies and guidelines are assumed as known, and will not be discussed in this review. Also, management of seizures in the pediatric realm is not discussed in this adult population-based review, because of the sheer volume of pediatric data present and the lack of expertise on the pediatric population of the authors, all of whom are adult practitioners. This article focuses on the current challenges across different practice settings, and discusses studies in various patient populations, including the pregnant, geriatric, those with HIV/AIDS, and comatose, psychiatric, and "pseudoseizure" patients, and offers possible evidence-based solutions or the expert opinion of the authors. Also included is information on newer AEDs, routes of administration and significant AED-related druginteraction tables.

\section{Epilepsy and seizures in pregnancy}

Seizures and epilepsy in pregnancy pose a unique set of challenges for the pregnant patient, the fetus, and the health care community. It is estimated that three to four births per 1,000 will be born to women with epilepsy (WWE), ${ }^{3,4}$ and these women when pregnant face a tenfold increase in odds of dying compared to the general population, greatly exceeding the two- to threefold increase in standardized mortality rate observed throughout life in people with epilepsy. ${ }^{5}$ Seizures and AEDs, which are the mainstay of treatment, pose significant problems to WWE at all stages, right from preconception/planning, through pregnancy and delivery, to the postpartum stage, affecting the infant too. In this section, prominent challenges during each stage, starting with pregnancy and ending with the appropriate planning required in the preconception stage, and best treatment strategies for seizures in this population are addressed.

Pregnancy in WWE poses such risks as potential teratogenic effects of AEDs, effects of maternal seizure on the mother and fetus, and genetic risk of seizures, all of which increase the chance of adverse outcomes. ${ }^{6}$ On the issue of AEDs, while it is known that there is a dose-associated increase in the risk of congenital malformations, ${ }^{7}$ there is enough evidence to believe that seizure control is less likely to be maintained in AED-untreated pregnancies. ${ }^{8}$ Even reductions in the concentrations of drugs like lamotrigine and oxcarbazepine have been associated with an increased seizure frequency. ${ }^{9,10} \mathrm{~A}$ detailed discussion on teratogenesis by AEDs is beyond the scope of this review. It must be noted that while structural teratogenesis is due to first-trimester exposure, cognitive ill effects are a likely risk with exposure throughout pregnancy. Valproic acid is the most incriminated cause of malformations, and is best avoided in preference to other agents.

Though there is no actual decrease in seizure threshold, numerous physiological changes during pregnancy cause pharmacokinetic alterations, including increased volume of distribution, elevated renal clearance, and induction of hepatic metabolism, making seizure control challenging. All these changes tend to decrease AED blood levels (ABLs). Specifically, glucuronidation induction decreases levels of lamotrigine and oxcarbazepine. Levetiracetam, phenytoin, phenobarbital, and zonisamide levels have been shown to decline $40 \%-70 \%$, while carbamazepine levels tend to remain largely unchanged. ${ }^{11,12}$ Reisinger et al performed a retrospective analysis on 115 pregnancies in 95 WWE to characterize the magnitude of clearance changes during pregnancy for multiple AEDs and to assess seizure frequency and factors increasing seizure risk in them. ${ }^{13}$ ABLs were recorded and changes in clearance and dose analyzed for an association between levels and seizure frequency. Lamotrigine and levetiracetam were found to have significant increases in clearance by $191 \%$ and $207 \%$, respectively, compared to nonpregnant baseline. Despite an increase in dose of most AEDs, an increase in seizures was noted in $38.4 \%$ of patients, while seizure deterioration was significantly more likely in patients with seizures in the 12 months prior to conception and those with localization-related epilepsy. The highest rates were among those on polytherapy, possibly because they had more severe epilepsy. Overall, seizures were found to worsen when AED levels fell $>35 \%$ from preconception levels. A lack of linear response between $\mathrm{ABL}$ decrease and increased seizure risk likely indicates the influence of other pregnancy-related factors contributing to breakthrough seizures, like hormone fluctuations, sleep-cycle disturbances, and heightened stress. ${ }^{14}$ American Academy of Neurology (AAN) practice parameters hence state that therapeutic drug-level monitoring during pregnancy should be considered for lamotrigine, carbamazepine, and phenytoin, while monitoring for levetiracetam and oxcarbazepine may be considered. ${ }^{11}$

The EURAP study, a prospective observational study from 42 countries, monitored 3,784 pregnant WWE and found $66.6 \%$ to be seizure-free, while a lamotrigine-treated group was found to be superior in terms of seizure control. ${ }^{15}$ Another prospective study of 1,297 pregnancies in WWE found that women who experienced seizures in the prepregnancy month had a 15 -fold greater risk of seizures during 
pregnancy. ${ }^{16}$ In accordance with these findings, the AAN guidelines note that seizure control in the preconception period is a significant predictor of seizure activity during pregnancy. ${ }^{17}$

Seizures affect pregnant women in many ways. It has been shown that WWE have an increased risk of gestational hypertension, but not preeclampsia. ${ }^{18,19}$ WWE who smoke during pregnancy seem to have a significant increase in the risk of preterm delivery compared to women without epilepsy who smoked. ${ }^{20}$ The investigators of the Kerala Registry of Epilepsy and Pregnancy prospectively followed a cohort of 375 pregnant WWE, investigated (among other things) infertility, and concluded that failure to conceive was significantly associated with using more than one AED, while taking three or more imparted a 20 -fold increased risk of not conceiving. ${ }^{21}$

Causes of seizures during pregnancy are many, as enumerated in Table 1. New-onset seizures during pregnancy should be assumed to be due to eclampsia or intracranial hemorrhage until proven otherwise. ${ }^{22,23}$ While causes like hyperemesis gravidarum can cause seizures from metabolic disturbances, cerebrovascular accidents, trauma, and tumors have seizure potential from structural and pathological disturbances. It is important to discuss two pregnancy-specific causes of seizures, preeclampsia and eclampsia, which account for about $10 \%-15 \%$ of maternal deaths. ${ }^{24}$ The pathophysiology is thought to be placental under perfusion and hypoxia that releases antiangiogenic factors that impair

Table I Causes of seizures in pregnancy

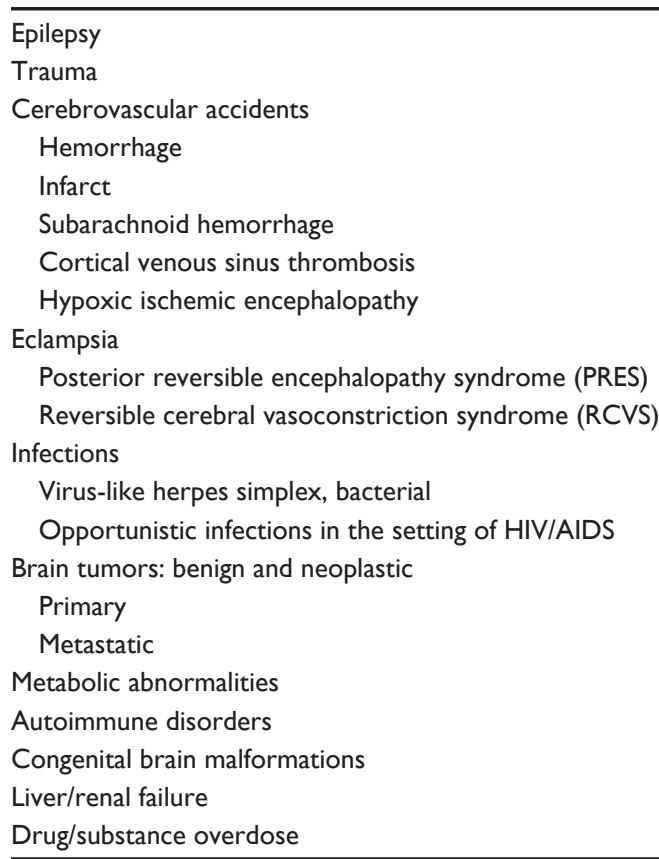

maternal endothelial function, leading to increased vascular permeability, vasoconstriction, activation of the coagulation cascade, and microangiopathic hemolysis. ${ }^{25}$ Neurologic complications like seizures, reversible cerebral vasoconstriction syndrome, encephalopathy, ischemic stroke, intracranial hemorrhage, and HELLP (hemolysis, elevated liver enzymes, low platelet count) syndrome can result from this and usually present by the 20th week of gestation, but can begin even in the postpartum period, 48 hours to 4 weeks after delivery.

Preeclampsia, defined as hypertension $(>140 / 90 \mathrm{mmHg})$, proteinuria (>300 mg per day), and peripheral edema, becomes eclampsia when the pregnant woman also experiences seizures. One in 400 mild and one in 50 severe preeclampsia patients develop seizures. ${ }^{26}$ Eclampsia can also lead to posterior reversible encephalopathy syndrome when there is a breakdown of cerebral autoregulation, often manifesting as a complex of headache, visual disturbances including cortical blindness, and generalized tonic-clonic seizures. The clinical challenge is to differentiate seizures from other causes and those because of eclampsia/posterior reversible encephalopathy syndrome. Magnesium sulfate is the treatment of choice for eclampsia-related seizures, where magnesium causes an increase in voltage-dependent blockade of the $N$-methyl-D-aspartate-type glutamate channels by preventing calcium influx, with glutamate being excitatory and contributing to epileptogenesis. ${ }^{27}$ The Eclampsia Trial Collaborative Group showed over two trials that magnesium is superior to both diazepam and phenytoin in the treatment of seizures. ${ }^{28}$ Magnesium is thought to protect the blood-brain barrier and limit cerebral edema formation, while it acts on cerebral and peripheral vasculature and causes vasodilatation. ${ }^{29}$ The next most important therapeutic intervention is to treat hypertension. Pulmonary edema and disseminated intravascular coagulation might be medical complications that will require immediate attention. For eclamptics with seizures, immediate delivery of the fetus after maternal stabilization is indicated.

While maternal seizures can cause falls, burns, and injury to the mother, there is an increased risk of obstetric sequelae like placental abruption, premature labor, and delivery. Pregnant WWE are hence at an increased risk of spontaneous abortion, premature induction of labor, cesarean section, and postpartum hemorrhage. ${ }^{30}$ Maternal seizures have an obvious adverse effect on the fetus by causing hypoxia and distress that manifest as fetal bradycardia, transient late decelerations, decreased beat-to-beat variability, and compensatory tachycardia, all of which reverse in 3-10 minutes after the convulsion terminates. ${ }^{31}$ It is considered safer to allow the 
fetus to recover in utero from the hypoxia and hypercarbia of maternal convulsions. If bradycardia and/or late decelerations persist beyond 10-15 minutes despite all resuscitative efforts, then emergency delivery should be considered. Breakthrough seizures may occur in WWE nearing term due to altered pharmacokinetics of AEDs. Seizure risk is highest during labor and the subsequent 24 hours, likely due to failure to take AEDs, impaired absorption, and sleep deprivation. ${ }^{32,33}$ The EURAP study found that seizures during delivery occurred in $2.6 \%$ of pregnancies in WWE on lamotrigine and carbamazepine, in 1.9\% in those using phenobarbital, and in $1.4 \%$ using valproic acid. ${ }^{15}$ The Kerala Registry of Epilepsy and Pregnancy found seizure relapse among women not on AEDs or on relatively low doses to be highest during the three peripartum days. ${ }^{16}$ Important advice during admission for delivery is to ask patients to bring in their own AEDs and adhere to their usual dosing regimen.

In the postpartum period, it is important to remember that the pharmacokinetics will return to prepregnancy levels within 10-14 days of delivery, so persisting with pregnancy doses after delivery can result in toxic levels of AEDs. It is useful to monitor levels and come up with a taper schedule over a week to 10 days following delivery. Most AEDs are excreted in breast milk, and are not a contraindication for breast-feeding infants.

Given all these challenges WWE face during pregnancy, the preconception period is most vital for planning a safe, prepared, and educated pregnancy, as indicated by practice guidelines. ${ }^{11,34}$ Prior to conception, every effort should be made to control seizures, especially generalized convulsions, establish individualized therapeutic levels of AEDs with at least two serum values before pregnancy, avoid valproate and phenobarbital, if possible, or use lowest effective dose, and aim for monotherapy, and both physician and patient should have a clear understanding of the problems and a plan to manage them. All these measures have been shown to improve pregnancy outcomes. ${ }^{35-37}$ While reviewing literature, we noted there seemed to be an incongruity between awareness of epilepsy/seizure-related issues during pregnancy and specific knowledge of the impacts, with only $7 \%$ of women knowing that being seizure-free in the 9 months prior to pregnancy increased their chances of being seizure-free during pregnancy, and only $6 \%$ knew that AED exposure in utero may have long-term neurodevelopmental effects on the fetus. ${ }^{38}$ Also, another study showed that only a third of WWE on AEDs associated with a risk of contraceptive failure knew of this risk. ${ }^{39}$ In addition, the more AEDs a women was taking, the poorer the knowledge of medication interactions, implying that those with severe forms of epilepsy were most likely to have contraceptive failure and greatest risk of unplanned pregnancy. ${ }^{39}$

It has been noted that there is a stark absence of research concerning the priorities and perspectives of WWE during pregnancy. The few studies have thrown light on the importance of behavioral research. Women need to come to terms with the counterintuitive knowledge that taking AEDs actually reduces risk. Another study found women with planned pregnancies were more likely to seek out information, perceive teratogenesis risks as more threatening, and proactively seek a "safe pregnancy" ${ }^{40}$ Preconception consultation, counseling, and planning by patient and physician is the key to managing epilepsy and seizures in pregnancy.

\section{Seizures in HIVIAIDS patients}

The HIV/AIDS population is prone to developing epilepsy for various reasons, such as opportunistic infection, direct central nervous system toxicity, and metabolic disturbance. AED use is complicated due to potential interactions with highly active antiretroviral therapy (HAART).

In the acute setting, the usual algorithms should be followed to abort seizure activity. For long-term treatment, specific dose adjustments may be necessary, and are outlined in guidelines from the International League Against Epilepsy. ${ }^{41}$ The recommendations are summarized in Table 2, which illustrates the relative paucity of good-quality studies that can guide the management of concurrent AEDs and HAART. Enzyme-inducing AEDs (such as phenytoin, primidone, phenobarbital, and carbamazepine) are associated with more adverse effects and should be avoided if possible, especially with the use of protease inhibitors and nonnucleoside reversetranscriptase inhibitors. ${ }^{41,42}$ Levetiracetam, lacosamide, gabapentin, and pregabalin appear to be the best choice in HIV/ AIDS patients with epilepsy and HAART. Based on expert opinion, these AEDs have the advantage of having minimal interactions with HAART, but they are expensive. ${ }^{43}$ Detailed

Table 2 Summary of ILAE recommendations regarding AEDs and HAART

\begin{tabular}{lll}
\hline AED & HAART & Dose adjustment \\
\hline Phenytoin & Lopinavir/ritonavir & Increase HAART 50\% \\
Valproic acid & Zidovudine & Decrease HAART dose \\
& Efavirenz & No adjustment \\
Lamotrigine & Ritonavir/atazanavir & Increase AED 50\% \\
& Raltegravir/atazanavir & No AED adjustment \\
Midazolam & Raltegravir & No AED adjustment \\
\hline
\end{tabular}

Abbreviations: ILAE, International League Against Epilepsy; AEDs, antiepileptic drugs; HAART, highly active antiretroviral therapy. 
studies have not been done. Yacoob et a $\mathrm{l}^{44}$ investigated the role of valproic acid in a small case series in a resource-poor setting. They reported excellent seizure and HIV control, suggesting that valproic acid is a safe and effective alternative to the more expensive AEDs.

Overlapping toxicities of AEDs, HAART, and the effects of HIV itself are another cause of clinical confusion. This makes it difficult to determine the etiology of such symptoms as weight loss, renal stones, hepatotoxicity, and osteoporosis. Overlapping toxicities should be identified so that those particular drug combinations can be avoided. ${ }^{45}$ Cardiovascular risk can be magnified by the use of concurrent protease-inhibitor and enzyme-inducing AEDs. Renal stones are associated with topiramate, zonisamide, and the protease inhibitors atazanavir and indinavir. HIV patients with hypogonadism should avoid using AEDs if possible. Tenofovir and prolonged AED use (especially phenytoin) are both associated with osteoporosis. An inexhaustive list of possible overlapping toxicities is shown in Table 3 .

Lee et $\mathrm{al}^{46}$ further investigated the effects of long-term exposure (6- and 12-month follow-up) in 55 patients with undetectable viral loads on HAART, prior to AED exposure. Contrary to expectation, they reported an increase in CD4 counts with the use of sodium-channel blockers that are known to interact with HAART (including phenytoin, carbamazepine, and lamotrigine). This small retrospective study suggested that the issues with interaction may not be as clinically serious as suggested by other studies, and that there might be immunological benefit from concurrent AED therapy.

Using prospective data from the CHASE study, Siddiqi et a ${ }^{47}$ investigated the utility of EEG in a resource-poor area of Zambia. They found that 23 of 81 patients had recurrent seizures. The same group also investigated the utility of neuroimaging in the CHASE cohort, concluding that it did not predict recurrent seizure. ${ }^{48}$ Investigators who studied the

Table 3 Overlapping toxicities

\begin{tabular}{llll}
\hline Symptom & AED & HAART & HIV \\
\hline Tremor & VPA & NA & + \\
Weight loss & TPM & NA & + \\
Hyperlipidemia & El (PHT, CBZ) & PI & + \\
Hypogonadism & El (PHT, CBZ) & NA & + \\
Renal stones & TPM & Atazanavir, indinavir & - \\
Hepatotoxicity & VPA, PHT & Multiple & - \\
Osteoporosis & El, prolonged AED use & Tenofovir & - \\
\hline
\end{tabular}

Abbreviations: AED, antiepileptic drug; CBZ, carbamazepine; El, enzyme inducer; HAART, highly active antiretroviral therapy; NA, not applicable; PHT, phenytoin; $\mathrm{Pl}$, protease inhibitor; TPM, topiramate; VPA, valproic acid. outcomes of HIV patients with epilepsy have found patient engagement to be a significant factor. Sikazwe et a ${ }^{49}$ reported that less than half of a cohort of 320 patients in Zambia chose to participate actively in treatment.

Overall, HIV/AIDS patients have a higher seizure burden compared to the general population, but they appear to be easy to control if properly treated. Enzyme-inducing AEDs should be avoided if possible. Newer AEDs have minimal interactions with HAART, but are not widely available in resource-poor settings. In that case, valproic acid may be a good alternative. The management of HIV-related seizures might be adequate without the use of routine EEG and neuroimaging in resource-poor settings.

\section{Epilepsy and seizures in older adults and dementia patients}

Seizures and epilepsy in the elderly population pose an ever-increasing challenge to health care as the geriatric population increases in size.$^{50}$ Twenty-five percent of newonset seizures are thought to occur in elderly over 65 years, given the bimodal peak of epilepsy. ${ }^{51}$ Of these, at least $10 \%$ are thought to be attributable to neurodegenerative conditions $^{52,53}$ and may be responsible for a sixfold-increased risk of seizures, specifically in Alzheimer's disease (AD). ${ }^{54}$ Recent studies have revealed that epilepsy could precede the onset of cognitive symptoms in AD by years in a subset of patients. ${ }^{55,56}$ Inciting events like stroke, tumors, trauma from falls, and organ-system dysfunction can all precipitate seizures, especially when coupled with preexisting dementia. Romanelli et al concluded from their study that focal seizures and seizures during mild dementia should prompt a search for a diagnosis different from dementia. ${ }^{57}$

Specific challenges arise when these conditions coexist, such as a marked worsening of cognitive and neurological function with seizures that is thought to accelerate cell death in dementia. ${ }^{58,59}$ Vossel et al analyzed 54 patients with amnesic mild cognitive impairment and AD with subclinical epileptiform abnormalities, and compared them with control patients with mild cognitive impairment or AD without epilepsy. The study group had an earlier onset of cognitive decline compared with the control group without epilepsy. ${ }^{56}$ A large proportion of elderly live in assisted-care facilities, which places an added burden on caregivers while worsening quality of life. ${ }^{51,60}$ Prolonged postictal periods also complicate care, and put them at higher risk of accidents and injuries. ${ }^{61}$ The next issue will be to diagnose seizures accurately, especially when the differential diagnoses can be as varied as syncope, transient ischemic attacks, transient global amnesia, 
arrhythmias, metabolic disturbances, and "psychogenic" episodes. Ictal confusion and staring may be the only signs of seizure with a lack of typical motor manifestations. They are often accompanied by prolonged postictal phases. The social setting makes obtaining an accurate history of the event and comorbidities difficult.

Diagnosing seizures needs a high degree of suspicion, as just indicated. EEG findings are fairly typical, and even show spatial predilection based on the type of dementia process, such as $\mathrm{AD}$ and disordered temporal activity. Consensus indicates that only patients with a second seizure or high risk of recurrent seizure should be treated, which brings us to the therapeutic challenges. A slew of pharmacokinetic changes complicate drug treatment in the elderly. AEDs like phenytoin are highly susceptible to aging changes, such as decreased total protein, albumin, and protein binding, and hence fluctuate as much as tenfold. ${ }^{62,63}$ Hepatic and renal disease can further complicate the picture. Hepatic mass, blood flow, and metabolism all diminish by about $10 \%$ for every decade after 40 years, particularly affecting the cytochrome P450 system that is responsible for metabolizing many AEDs. Renally cleared drugs like levetiracetam, topiramate, and gabapentin are affected with age-related decrease in glomerular filtration rate. It is important to titrate doses more accurately and obtain drug levels during management.

Choosing the right AED can be tricky for these reasons. A Veterans Affairs cooperative study randomized patients aged 60 years and older with new-onset seizures to receive gabapentin, lamotrigine, or carbamazepine. ${ }^{64}$ At the end of 1 year, patients on lamotrigine showed the best retention, while those on carbamazepine showed the worst. A previous study by Brodie et al showed a similar finding, with patients on carbamazepine having a higher dropout rate than lamotrigine. ${ }^{65}$ An AED that potentially treats seizures while helping with other symptoms of dementia can be very useful, especially in avoiding polypharmacy. Valproate has some mood-stabilizing properties, but the sheer burden of side effects makes it a poor candidate. In a randomized trial of levetiracetam, phenobarbital, and lamotrigine in patients with $\mathrm{AD}, 58 \%-71 \%$ of the patients had $>50 \%$ seizure reduction during a 1-year period. Levetiracetam had the most favorable profile on cognition, although lamotrigine showed the most positive effect on mood. ${ }^{66}$ Similar results have been shown in other trials on AD patients. ${ }^{67,68}$ Some neuropsychiatric symptoms can worsen in susceptible older adults on levetiracetam. Older-generation AEDs like phenytoin, phenobarbital, and valproate tend to have more cognitive effects, while topiramate can worsen verbal memory, attention, and cognitive speed in the elderly. ${ }^{69}$ Increasingly, lacosamide is being used, but no real studies have been conducted in the elderly with this agent.

Side effects and drug interactions are a further impediment in elderly and demented patients, owing to polypharmacy and lifestyle. Such problems as osteoporosis, cardiac risk-factor worsening, and toxicity of other agents on withdrawal of AEDs can all be serious. Brain tumors are more common in the elderly, cause seizures, require patients to be on AEDs as well as cancer chemotherapy, and pose a unique challenge. Enzyme inducers can decrease the level of chemotherapeutic agents. $N$-methyl-D-aspartate receptor antagonists and acetylcholinesterase inhibitors that are used in the treatment of dementia do not have established seizure threshold-lowering properties. Among antidepressants, most are safe, with the exception of bupropion, which is known to increase seizure risk. ${ }^{70}$ While the general practice is to avoid first-generation antipsychotics, this is based on weak observational data. Among second-generation agents, clozapine is an established seizure risk, ${ }^{71}$ and a meta-analysis showed the seizure incidence to be high in clozapine, olanzapine, and quetiapine compared to placebo, while risperidone and ziprasidone did not have a high incidence. ${ }^{72}$ Two other pharmacovigilance studies had users of clozapine, olanzapine, and quetiapine report more frequent seizures than those of risperidone, amisulpride, and aripiprazole. ${ }^{73,74} \mathrm{~A}$ recent observational study by Bloechliger et al confirmed these findings in dementia patients, where use of first-generation antipsychotics and newer agents like olanzapine and quetiapine (clozapine use limited in the UK) was linked to higher seizure risk compared to nonuse, and those dementia patients on new agents like risperidone, amisulpride, aripiprazole, and sulpiride were not at a higher risk for seizures. ${ }^{75}$ There was a two- to threefold increase in seizure risk among antipsychotic users, irrespective of class. Interestingly, they showed that patients with dementia had a higher seizure risk compared to those with affective disorders, and seizure risk in dementia was increased irrespective of antipsychotic use. ${ }^{75}$

\section{EEG, hypothermia, coma, and nonconvulsive status epilepticus}

EEG is an invaluable tool for the diagnosis and management of seizures. Continuous video EEG (cEEG) and quantitative EEG (qEEG) are powerful tools that have become increasingly available, but survey data reveal significant variability in utilization. ${ }^{76,77}$ This is likely due to lack of clear evidence guiding the duration and method of monitoring the EEG. ${ }^{77}$ cEEG is resource-intensive, which makes it difficult to utilize, and the benefit to patient outcome is not firmly established. ${ }^{78}$ The successful implementation of cEEG is predicated on 
the availability of trained EEG technicians for setup and staff to review the recording in real time. Adequate staffing and equipment are typically not readily available outside academic centers.

Current guidelines indicate the use of cEEG in altered mental status following seizure, intracranial hemorrhage, and coma for the detection of nonconvulsive seizures (NCSs) ${ }^{79}$ Due to the nature of the patient population, cEEG/qEEG is used frequently in the intensive care unit setting.

Foreman et $\mathrm{al}^{80}$ performed a retrospective case-control study with critically ill patients, assessing the prognostic value of generalized periodic epileptiform discharges (GPEDs). They found no significant difference in outcome (51.5\% with GPEDs had poor outcome versus $46.5 \%$ of controls). Their findings reported an association with worse outcome in nonconvulsive SE (NCSE).

Oddo et al ${ }^{81}$ sought to elucidate the prognostic value of cEEG in medical intensive care unit patients without acute neurologic issues using a retrospective study. A subgroup analysis of 120 patients controlling for age, coma, shock, acute renal failure, and acute hepatic failure showed significantly worse outcomes in patients with NCS or generalized periodic discharges.

These case-control and retrospective studies suggest that cEEG and detection of NCSE/GPEDs have prognostic value in the intensive care unit setting. ${ }^{80,81}$ However, survey data show that there is significant interobserver variability in the interpretation of the EEG, likely due to the lack of standardized electrographic criteria for the diagnosis of NCSE. ${ }^{82,83}$ Further studies are needed to standardize the electrographic diagnosis and treatment of NCSE and to determine if this is beneficial to patients.

Stewart et al $^{84}$ performed a small blinded study comparing the accuracy of a neurophysiologist reading raw EEG data to neurophysiologists (with 2 hours of training and no prior experience with qEEG) reading qEEG data in identifying seizures. Compared to raw EEG (gold standard for seizure identification), the median sensitivity was $83.3 \%$ for colordensity spectral array and $81.5 \%$ for amplitude-integrated EEG. The true accuracy of qEEG techniques as a screening tool are likely better than reported in this study, due to the fact that the experimental group had to be blinded to the raw EEG data, which would normally be available in practice. qEEG may help nurses and technicians screen for seizures at the bedside as they do with cardiac telemetry, but this idea will require further study.

As per the experience at our institution, neurotelemetry/ remote access allows a limited number of physicians to monitor cEEG effectively. Our institution also employs the help of resident physicians, especially for monitoring after hours. Other institutions include EEG technicians and nurses in the monitoring process. qEEG techniques can be helpful for screening large amounts of EEG data.

A small prospective study by Yigit et $\mathrm{al}^{85}$ sought to elucidate the role of EEG in the emergency department (ED) setting. A total of 110 patients were enrolled who presented with seizure-like events. All patients were clinically evaluated by neurologists and ED physicians prior to routine EEG. The sensitivity and specificity of ED physicians' diagnosis was $88 \%$, with moderate interobserver reliability with neurologists. The authors made the assertion that most patients do not require an EEG in the ED to diagnose the presence of clinical seizure, although the use of EEG was very helpful in therapeutic decision making.

Small observational studies have examined the role of cerebral hyperperfusion as an adjunct/alternative for detecting NCSE using perfusion computed tomography or transcranial Doppler. ${ }^{86,87}$ These technologies are more readily available than EEG, and may be helpful in acute settings. Less equipped EDs and hospitals may do well to transfer patients who need cEEG to academic centers until they develop the ability to perform the procedure adequately.

The AAN released guidelines on the neurologic management and prognostication of post-cardiac arrest and cardiopulmonary resuscitation patients in $2006 .{ }^{88}$ The advent of therapeutic hypothermia (TH) was a major new advancement that has necessitated reevaluation of how these patients are managed. In the American Heart Association guidelines, Peberdy et $\mathrm{al}^{89}$ advocate for the use of frequent or continuous EEG monitoring during TH. The use of cEEG monitoring during $\mathrm{TH}$ has brought to the forefront the possibility of postanoxic seizures and NCSE. Knight et $\mathrm{a}^{90}$ and Rittenberger et $\mathrm{al}^{91}$ reported a high incidence of seizures/NCSE associated with poor outcome. There is uncertainty regarding the benefit of detecting, treating, and prognostic value of NCS and NCSE in this patient population, and it has been a very active area of research.

One of the few clinical markers in the AAN guidelines that was strongly predictive of poor outcome was myoclonic SE (MSE). The guidelines make note that sporadic myoclonus and seizures were not predictive of poor outcome. The heterogeneity of MSE sometimes makes it difficult to distinguish from sporadic myoclonus or Lance-Adams syndrome (LAS), which have more favorable prognosis. ${ }^{92}$ Classically, LAS is a late-onset myoclonus that occurs after the patient has regained consciousness, but it can be confused with MSE when it occurs during coma. ${ }^{93,94}$ MSE usually occurs within 24 hours, whereas LAS usually takes days to weeks to 
develop. LAS is typically associated with respiratory arrest (rather than cardiac arrest), and is usually associated with intentional movements.

In a recent review by Crepeau et al, ${ }^{95}$ the significance of common EEG patterns did not seem to be altered by $\mathrm{TH}$, despite the fact that $\mathrm{TH}$ in itself causes decreased amplitude and frequency. As per the AAN guidelines, ${ }^{88}$ there is not enough evidence to use EEG patterns in isolation for prognostication. Multiple recent studies have continued to show the overall benefit of cEEG monitoring in TH.

Dragancea et $\mathrm{al}^{96}$ performed a retrospective study investigating the effect of electrographic SE on outcome in cardiac arrest and TH. There were 41 of 127 (32\%) patients who developed NCSE, and those who survived all had continuous EEG background, preserved $\mathrm{N}_{20}$ peaks on somatosensory evoked potential, and low/moderate neuron-specific enolase (18-37 $\mu \mathrm{g} / \mathrm{L})$. Sadaka et $\mathrm{al}^{97}$ retrospectively validated EEG patterns (burst suppression and NCSs) as poor-outcome predictors even in the setting of TH. Their data showed uniformly poor outcomes for patients with NCSs or burst suppression. Maia et $\mathrm{al}^{98}$ published a retrospective analysis on 26 subjects, also confirming the accuracy of a multimodal approach (absent brain-stem reflexes, absent $\mathrm{N}_{20}$, malignant EEG pattern). Multiple authors have recommended delaying prognostication until 72 hours postarrest to avoid premature withdrawal of care. ${ }^{99-102}$

The issue of how the utility of EEG is changed by TH was investigated by Tjepkema-Cloostermans et al. ${ }^{103}$ There were 142 patients with cardiac arrest and treatment with $\mathrm{TH}$ who were prospectively studied. EEG patterns were analyzed in a blinded fashion, showing poor outcomes with isoelectric and low voltage EEG, and burst suppression with identical burst patterns at 24 hours. Mani et al ${ }^{104}$ also sought to prove the prognostic value of EEG with a retrospective analysis on 36 patients; $94 \%$ of patients with epileptiform activity and $100 \%$ of patients with electrographic seizures had poor outcomes.

Amorim et $\mathrm{al}^{105}$ performed a single center retrospective study investigating the significance of malignant EEG patterns (GPEDs, seizures, SE, myoclonic SE) on outcome in post-cardiac arrest and TH; 33\% of patients survived to discharge. Good neurological outcomes were observed in 11\% of patients with malignant EEG patterns and $36 \%$ of patients with "pure" burst suppression. The authors concluded that malignant EEG patterns did not predict poor neurologic function in this study. Pure burst suppression was confounded by anesthetic use, so conclusions were not made on its prognostic significance. Alvarez et al ${ }^{106}$ performed a small prospective study assessing the significance of stimulus-induced rhythmic periodic or ictal discharges (SIRPIDs) in TH patients. In their 105-patient cohort, SIRPIDs were associated with poor neurologic outcome. SIRPIDs also occurred in conjunction with other EEG markers of poor neurologic outcome (such as discontinuous background). Rossetti et al ${ }^{107}$ prospectively investigated the prognostic value of cEEG in TH. Among the 34 patients, $75 \%$ of the nonsurvivors had a nonreactive background. This finding was not noted in any of the survivors. Rundgren et al ${ }^{108}$ used amplitude-integrated EEG in a prospective observational study to assess the prognostic value of EEG. They found continuous backgrounds to be associated with return of consciousness. Burst-suppression patterns were associated with persistent coma and death. Flat EEG at the onset had no prognostic value.

Many TH patients accumulate massive amounts of cEEG data, which leads to the possibility that qEEG techniques could be of use. Burjek et al ${ }^{109}$ investigated the use of bispectral index score (BIS) as a possible prognostic indicator. The group hypothesized that more injured brains would require less sedation and yield a lower BIS. They reported a 54\% increase in the odds of poor outcome for every 10-point decrease in BIS. Riker et al ${ }^{110}$ retrospectively analyzed BIS data in seven patients who awoke prior to completion of TH. The study suggests that high BIS after neuromuscular blockade may predict good outcome.

Outside cardiac arrest, there is little evidence on other uses of TH. Animal models have suggested that TH may mitigate some of the pathophysiologic changes induced by SE, and may even be a useful treatment option. ${ }^{11-114}$ Some groups have studied TH in the treatment of refractory SE (RSE) in humans (not related to cardiac arrest or anoxic injury), but results have been conflicting. Marchi et al ${ }^{115}$ performed a retrospective analysis of 50 patients with RSE who were treated with TH. The TH group overall had worse outcomes compared to the rest of the cohort. Multiple review articles have been published espousing the potential benefits of TH in the treatment of RSE and the need for further study. ${ }^{116,117}$

One of the other issues with cEEG in the use of TH is cost. Crepeau et $\mathrm{al}^{118}$ performed a retrospective study confirming the increased cost of routinely using cEEG in every TH patient (US\$1,571.59/patient with routine EEG versus \$4,214.93/ patient on cEEG), without a clear benefit in terms of outcome. Alvarez et $\mathrm{al}^{119}$ tested the yield of intermittent EEG versus cEEG in a prospective cohort of 34 patients with cardiac arrest and $\mathrm{TH}$, and found that intermittent EEG may be an option for neuromonitoring in TH if cEEG is unavailable or too costly.

\section{Psychogenic nonepileptic seizures (“pseudoseizures")}

Patients who experience psychogenic nonepileptic spells (PNES) or "pseudoseizures" are yet another diagnostic and 
therapeutic challenge. Often, it can be difficult to distinguish between PNES and organic seizures, and the picture can be further complicated when both occur simultaneously. ${ }^{120,121}$ Diagnosis can be straightforward if an event can be witnessed or captured on video EEG. In 2013, the International League Against Epilepsy released guidelines to assist with clinical diagnosis of PNES in situations where video EEG is not available. ${ }^{122}$

The basic pathophysiology is still poorly understood. There is a growing body of evidence that underlying structural abnormalities may contribute. Arthuis et al ${ }^{123}$ performed an imaging study with positron-emission tomography that noted anterior cingulate and right parietal hypometabolism associated with PNES. These areas are involved in regulation of emotion and consciousness. Lee et al ${ }^{124}$ examined whitematter tracts using diffusion-tensor imaging and noted lefthemispheric abnormalities. Xue et al ${ }^{125}$ used EEG-network analysis to demonstrate abnormalities in connectivity between the frontal lobe and other regions. Reinsberger et $\mathrm{al}^{126}$ suggested autonomic dysfunction may play a role in the pathogenesis of PNES. They identified PNES patients with heart rate-variability analysis. The role of autonomic dysfunction is an area of future research that may yield novel ways to conceptualize, diagnose, and treat PNES.

Inconclusive results after prolonged intensive video EEG monitoring is a frustrating reality that is more likely to occur in PNES patients. ${ }^{127}$ Popkirov et al ${ }^{128}$ and Goyal et al ${ }^{129}$ tested the utility of different induction techniques specifically to provoke nonepileptic events. Compression of temple region, verbal suggestion, tuning-fork application, moist-swab application, torchlight stimulation, and saline injection all had $100 \%$ specificity and positive predictive value for PNES. One group ${ }^{130}$ postulated that multiple complaints on a review of systems would be a helpful clinical marker when the diagnosis is unclear.

Capturing a PNES event on cEEG may not always be feasible. Cost and access are barriers, so other reliable methods need to be available. Gubbi et a ${ }^{131}$ addressed the issue by developing a wearable device with a $100 \%$ PNESidentification rate that could aid the diagnostic process. Beniczky et al ${ }^{132}$ developed an algorithm using surface electromyography to analyze convulsive events with $95 \%$ accuracy. These are promising new technologies that may have a great impact on cost and convenience to patients and the health care system in the future.

Often the best information available to clinicians is from eyewitnesses accounts. Ristić et a ${ }^{133}$ showed that better medical education of the observer improved the accuracy of event classification as epileptic and nonepileptic. Alessi and Valente ${ }^{134}$ warned that PNES patients are highly susceptible to a placebo effect, so improvement with AEDs is not a very reliable clinical marker to distinguish epileptic seizures from PNES. Despite this, response to AED treatment is commonly used to assess the likelihood of nonepileptic events.

There are few high-quality studies addressing the treatment of PNES, despite its high incidence ${ }^{121,135,136}$ (1.4 4.9/100,000). ${ }^{135}$ Cognitive behavioral therapy (CBT) has been shown to be successful in two small prospective clinical trials. ${ }^{137,138}$ Goldstein et al ${ }^{138}$ performed a pilot randomized controlled trial comparing CBT to standard medical care, and found that CBT was superior in terms of PNES resolution at 3 months. LaFrance et $\mathrm{al}^{137}$ also investigated PNES in a prospective manner by recruiting video EEG-confirmed PNES patients to a standardized CBT protocol. Seizure frequency was measured before and after the intervention in 17 patients, and a significant decrease in mean seizure frequency was noted. Santos et al ${ }^{139}$ demonstrated the usefulness of psychoanalytical therapy in 37 patients. Psychoeducational ${ }^{137}$ and mindfulness-based ${ }^{140}$ interventions also have some evidence of usefulness.

Small pilot studies have shown encouraging results for the use of venlafaxine ${ }^{121}$ and sertraline. ${ }^{141}$ Pintor et al ${ }^{121}$ conducted an open-label prospective study in patients with PNES and depression/anxiety treated with venlafaxine, where the number of seizures decreased by over $50 \%$ in 15 patients. LaFrance et a ${ }^{141}$ conducted a pilot double-blinded, randomized trial investigating the effect of flexible-dose sertraline versus placebo. The group treated with sertraline had a $45 \%$ reduction in seizure frequency versus an $8 \%$ increase in the placebo group. LaFrance et al also performed a second randomized controlled trial ${ }^{142}$ comparing variable-dose sertraline alone, CBT alone, and a combination of the two. The combined arm showed $59.3 \%$ seizure reduction, the CBT-alone arm had 51.4\% seizure reduction, and the sertraline-alone arm showed no significant effect on seizure frequency.

PNES patients typically have comorbid psychiatric and psychosocial issues, which contribute to the difficulty in successful treatment. One retrospective and another prospective population-based study reported patients' economic hardships were associated with poor outcomes, ${ }^{136,143}$ so it may be helpful to be aggressive in dealing with these social issues in a multidisciplinary manner. Based on a prospective study on 260 subjects, McKenzie et al ${ }^{143}$ reported that PNES resolution in patients with social security income was 2.34 times less likely and in those with depression/anxiety 2.32 times less likely. Duncan et al ${ }^{136}$ published a retrospective study that showed employed subjects were 4.89 times more likely to be free of spells at follow-up than the unemployed. One recently 
published paper ${ }^{144}$ suggested that patients with comorbid epilepsy were more likely to improve over time. Over approximately 4 years of follow-up, they found that $22 \%$ of the PNES patients and $58 \%$ of PNES/epilepsy patients had a decrease in nonepileptic events.

The literature suggests that clear disclosure of the diagnosis to the patient is associated with cessation or decreased frequency of nonepileptic events. ${ }^{145,146}$ A prospective audit by Razvi et a ${ }^{146}$ showed a decrease in health care utilization after diagnosis. Their data reported a rapid decrease in health care demand in 28 subjects (including a 100\% decrease in hospitalization) directly correlated with the establishment of a PNES diagnosis. Mayor et a ${ }^{145}$ did a feasibility study on a standardized psychoeducational intervention that could be delivered by health care professionals (nurses, psychology assistants) with little experience in psychological therapy. Their tool resulted in 50\%-100\% reduction in PNES frequency. These studies illustrate the importance of prompt diagnosis and clear communication (even from nonphysicians), which may improve outcomes for the patient and have a positive impact on health care spending.

In the hospital setting, many clinicians are tempted to ask for inpatient psychiatric consultation (IPC) when PNES is suspected. Acton and Tatum ${ }^{120}$ published a survey of 173 centers certified by the National Association of Epilepsy Centers investigating the use of IPC in epilepsy-monitoring units and a small, single-center, retrospective analysis of the use of IPC for newly diagnosed PNES. More than 50\% of surveyed centers did not routinely obtain IPC, and in the single-center cohort 19 of 26 subjects agreed to IPC. The overall conclusion of the authors was that there was no obvious benefit to IPC, but larger trials were warranted. Case-by-case use of IPC will likely facilitate more timely evaluation and treatment of the minority of patients who would benefit from IPC, such as in the case of psychosis or suicidal ideation. Their data also suggested that major barriers to treatment included patients' acceptance of the diagnosis and availability of physicians willing to manage PNES. As with many psychiatric conditions, very little can be offered until the patient is ready to be treated.

Although PNES in itself is not a life-threatening condition, these patients are at significant risk for iatrogenic harm. ${ }^{147}$ The emergency room setting is particularly dangerous, since patients are often treated aggressively before all details of medical history are available. Another patient population with a unique risk are the pregnant, who may be exposed unnecessarily to the risks of AED treatment. Patients with PNES are also at risk of sustaining injury from their events, much like epileptic seizures. ${ }^{147,148}$

\section{Seizures and psychiatric comorbidities}

Psychiatric comorbidities are more frequent in patients with epilepsy compared to the general population. Treatment of these comorbidities is complicated by the interplay between antipsychotics, antidepressants, AEDs, and their effect on symptoms.

The relationship between depression and epilepsy is complex. Kanner et al ${ }^{149}$ published a paper detailing the current understanding of the links between depression and epilepsy. They stated that there was a multifactorial and bidirectional relationship between the two conditions. Epidemiologic data show that having major depressive disorder is linked to the development of medical and neurological disease, including epilepsy. Patients who have an established diagnosis of epilepsy are at higher risk of developing depression. Animal models also demonstrate this link through the presence of depressive behaviors in epileptic rats.

The link between epilepsy and depression is important, because it is common and complicates treatment. Recognition that depression and related issues are common among epilepsy patients is crucial for management. Karouni et al ${ }^{150}$ reported that depression may be undertreated in the epilepsy population. Reisenger and Dilorio ${ }^{151}$ asserted that depression was the most common psychiatric comorbidity. The authors analyzed survey data from Project EASE (Epilepsy Awareness, Support, and Education). Employment status, social support, and stigma were the three most consistent predictive factors in the development of depression in study subjects. One of the most dangerous aspects of depression is the risk of suicide. Hecimovic et al ${ }^{152}$ looked at the risk of suicidal ideation in the epilepsy population. In their prospective study, they found that $10.9 \%$ of the 193 patients enrolled admitted to suicidal thoughts. Depression was the only factor that had a significant correlation, but $25 \%$ of the cohort either had no depression or only mild depression. Another issue associated with depression is substance abuse. Sajatovic et al ${ }^{153}$ recently had published a retrospective study comparing the hospitalization and emergency room visits of epileptic patients with and without comorbid mental illness. They found that hospitalization or ED visits occurred at least once per year in $34.2 \%$ of the epilepsy-only group, and were significantly higher in the comorbid mental illness group (50\%). Most of the emergent care was directly related to seizure complications, but substance abuse was also a very common issue that brought the comorbid mental illness patients to the hospital. Crail-Meléndez et al ${ }^{154}$ sought to address the high prevalence of depression by testing CBT in patients with temporal lobe epilepsy. Their data showed significant improvement in Beck Depression Inventory and Quality of Life in Epilepsy-31 scores after 16 weekly sessions. 
Depression is not the only neuropsychiatric comorbidity associated with epilepsy. Many epilepsy patients have associated intellectual disability, which puts them at risk of behavioral problems. ${ }^{155}$ Behavior disturbances in this population have to be carefully evaluated, since the etiology can be diverse. Medical issues, AED effects, psychiatric issues, and even seizure are some of the possibilities.

Schizophrenia and other psychoses also occur in concert with seizures, making it a significant challenge for the patient, in terms of managing symptoms, caregivers in terms of help, and physicians in terms of treatment. It is believed that epilepsy is a risk factor for psychosis, and a recent systematic review of literature and meta-analysis of studies by Clancy et $\mathrm{al}^{156}$ revealed a $5.6 \%$ pooled prevalence of psychosis in epilepsy and a rate of psychosis among epileptics to be 7.8 times higher than in people without epilepsy. The same study found an incidence of postictal psychosis (PIP) to be $\sim 2 \%$, lower than previously reported, perhaps because of the transient nature of the condition. The rate of interictal psychosis (IIP) was $5.2 \%$. Temporal lobe epilepsy had the highest rate of psychosis. The issue of association versus causation between epilepsy and psychosis is much debated, without definitive answers. Theories of "kindling", "forced normalization", and ongoing subictal activity in the limbic system have been proposed to explain psychosis in epilepsy.

Clinically, it is important to distinguish IIP and PIP from primary psychiatric disease, because there is a difference in terms of treatment and prognosis. Currently, there are no consensus guidelines on the treatment of IIP and PIP. Adachi et a ${ }^{157,158}$ have had published reviews on the management of IIP/PIP, and offered advice on the best management strategies. IIP appears to be more associated with developmental/ intellectual delays and complex partial seizures. Polypharmacy and AED use is also associated with IIP. Ethosuximide, phenytoin, zonisamide, topiramate, and vigabatrin have been associated with higher risk of IIP. Treatment of IIP can be difficult in multiple ways. Typically, the treating physician who encounters these symptoms may not be experienced in treating psychosis, and the use of antipsychotics may have a detrimental effect on seizure control. The authors suggested that the epileptologist is in the best position to recognize and initiate treatment. The preexisting therapeutic relationship removes some of the barriers to the initiation of psychiatric treatment. Antipsychotics should be used early, but there is no clear evidence that any particular agent is better suited for this indication. Aside from symptomatic management, treatment should also address functional recovery and quality of life (including psychotherapy and social support). PIP is easier to recognize, since it is clearly associated with seizure activity. Milder changes in behavior (elated mood, irritability) may herald frank psychosis, which can be prevented with early treatment. PIP is typically associated with focal-onset epilepsies (especially long-standing temporal lobe epilepsy). Unlike IIP, PIP can improve with improved seizure control. While IIP should be treated similarly to functional conditions (such as schizophrenia), PIP should focus on halting dangerous behaviors. Duration of antipsychotic treatment is an area of active research. Mula ${ }^{159}$ published a review that stressed the importance of distinguishing IIP/PIP from primary psychiatric disease. The author recommended citalopram for mood disorders, and newer antipsychotics (olanzapine, risperidone, quetiapine) for IIP.

\section{Psychotropic medications and seizures}

Physicians who treat epileptic patients with psychiatric comorbidities must be cognizant of the effects of psychotropic drugs. There is conflicting evidence regarding the relationship between psychotropic drugs and seizure control. In general, most clinicians are concerned about decreased seizure control with concomitant AED and antipsychotic use. Antipsychotics and antidepressants, most notably haloperidol, risperidone, chlorpromazine, clomipramine, and sertraline, can cause increased concentrations of carbamazepine, valproic acid, phenytoin, phenobarbital, and lamotrigine. ${ }^{160}$

Clozapine in particular is known to cause seizures as a side effect. A recent review ${ }^{161}$ reported that this risk was typically highest at serum concentrations $>1,300 \mathrm{ng} / \mathrm{mL}$. The use of AEDs for primary seizure prophylaxis is discouraged, due to risk of cumulative side effects and drug interactions that may alter the serum level. Even in the case of secondary prophylaxis, the dose of clozapine should be adjusted. The use of AEDs should be considered a last resort. Topiramate, gabapentin, and lamotrigine are reasonable choices (although lamotrigine may increase the clozapine serum level). Carbamazepine, phenytoin, and phenobarbital may decrease the clozapine serum concentration. Additionally, carbamazepine should be avoided, due to increased risk of agranulocytosis.

Bloechliger et $\mathrm{al}^{75}$ performed a retrospective study to determine which antipsychotics were most associated with increased risk of seizure, and found that patients with affective disorders who used higher-potency first-generation antipsychotics (haloperidol, prochlorperazine, trifluoperazine) had a 2.5-fold increased risk of developing seizures. Okazaki et al ${ }^{162}$ performed a prospective study that compared the effect of multiple types of antipsychotics on seizure frequency. They concluded that antipsychotics did not increase 
the number of seizures, and their use could actually improve seizure frequency in focal-onset epilepsy. Levine and Ruha ${ }^{163}$ published a review on antipsychotic overdose. They reported that seizures were most associated with clozapine, and were otherwise not common with atypical antipsychotic overdose. They recommended treating drug-induced seizures with benzodiazepine and barbiturates. The authors discouraged the use of AEDs for toxin-induced seizures.

\section{Novel AEDs and new routes of drug administration}

A number of new AEDs have entered the market in the last 20 years, and there are newer ones in development. They have been quite a boon in terms of reduced side effects compared to the older agents. Important characteristics of these drugs are summarized in Table 4. Drug interactions between AEDs and other classes of medications like HAART, anticoagulants, and psychotropic medications are summarized in Table 5.

Most AEDs used in the acute setting can be given intravenously. While this can be a great advantage, it can also be a frustrating challenge. In the prehospital setting in particular, intravenous (IV) access may not be available. It is for this reason that the search and use of alternate routes of administration become important.

The introduction of rectal diazepam was an excellent solution for the pediatric population (for whom IV access is more difficult to establish), but is proving to be uncomfortable and invasive for older children and adults. Rectal diazepam is the only alternative that is FDA-approved in the US as an alternative to the IV route in the treatment of acute seizures. Intramuscular, intranasal (IN), buccal, and sublingual formulations of benzodiazepines have been studied in the use of prolonged and repetitive seizures.

Intramuscular autoinjectors (AIs) appear to be a promising alternative in terms of safety and efficacy, based on randomized controlled trials and pharmacokinetic studies. ${ }^{164,165}$ Garnett et al ${ }^{166}$ compared the pharmacokinetic and safety profile of a diazepam AI and rectal diazepam in a single-center, open-label study. They concluded that the AI consistently had more rapid and reliable absorption (maximum concentration $303.9 \mathrm{ng} / \mathrm{mL}$ in the AI group versus $209.1 \mathrm{ng} / \mathrm{mL}$ in rectal administration group). Lamson et $\mathrm{al}^{167}$ also compared the two routes of access, and found 14\% greater bioavailability with an AI. Abou-Khalil et al ${ }^{168}$ performed a double-blind, placebo-controlled study with a diazepam AI administered by caregivers for acute repetitive seizures in the outpatient setting. The diazepam AI significantly increased the time until the occurrence of the next seizure (absolute risk reduction of
$20.2 \%$ ). All three studies reported excellent tolerability, with the major adverse effect being injection-site pain. Despite the fact that most of these studies were either affiliated to or funded by the pharmaceutical industry, the potential benefit seems clear.

Henney et al performed a randomized controlled study in the hospital setting comparing the bioavailability and tolerability of IN diazepam to the standard rectal formulation in adults, ${ }^{169,170}$ and concluded that the two were equivalent. Ivaturi et al ${ }^{171}$ also reported comparable bioavailability in a cohort of healthy volunteers. Thakker and Shanbag ${ }^{170}$ prospectively investigated the safety and efficacy of IN midazolam compared to IV diazepam in children. The time from hospital arrival to treatment was shorter in the IN midazolam group. Time from arrival to hospital and cessation of seizures was also shorter in the IN midazolam group. de Haan et al ${ }^{172}$ compared IN midazolam to rectal diazepam administered by caregivers to institutionalized adult patients and found comparable efficacies. Overall, the IN formulation appears to be a viable option.

Buccal midazolam has recently been licensed in Europe, and there have been multiple small international trials demonstrating safety and efficacy. ${ }^{173}$ This option has not been studied in the US population. Nakken and Lossius ${ }^{174}$ compared buccal midazolam to rectal diazepam in SE, and found that buccal midazolam actually stopped seizures more quickly.

Many of the studies involving rectal administration in the prehospital setting included data on caregiver preferences, and all have demonstrated a clear preference for alternative routes. As evidence suggests, especially in the prehospital setting, the value of routes that preclude the need for IV access to commence treatment of seizures need to be adopted. Further randomized studies and FDA approval will facilitate this.

\section{Conclusion}

As evidenced from the above discussion, the challenges in the realm of seizures and epilepsy are myriad and unique to each setting. This review has tried to address only some of these issues that any practitioner who deals with the acute management of seizures may encounter. Our aim has been to update the reader on all the new research, guidelines, and tools available to answer these questions and provide solutions to these situations. It is by no means a complete read on the field, given the vastness of the topic and various subspecialties involved. Specifically, for seizures and epilepsy in the pediatric setting, we direct the reader to other available literature. The document also highlights the numerous 


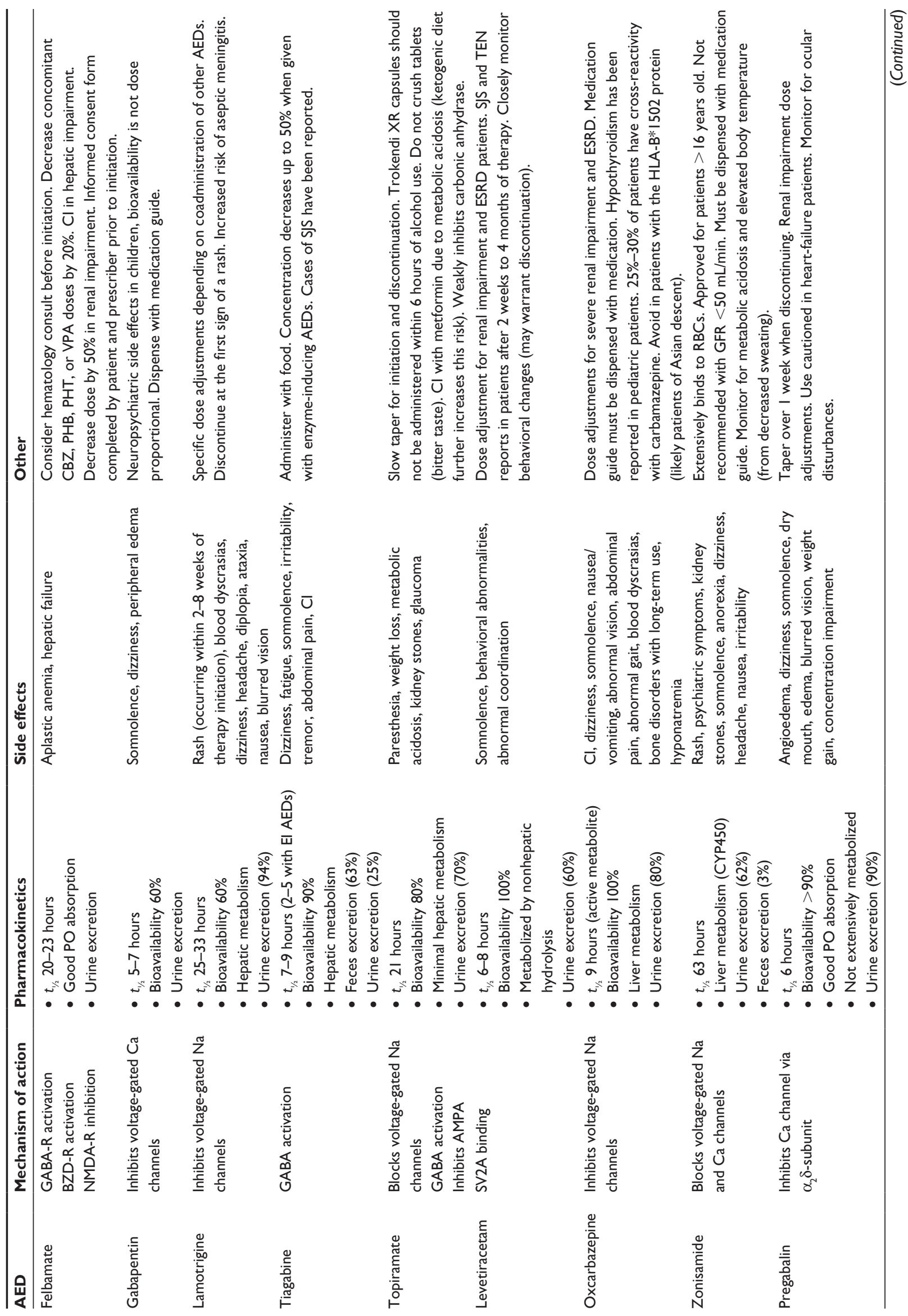




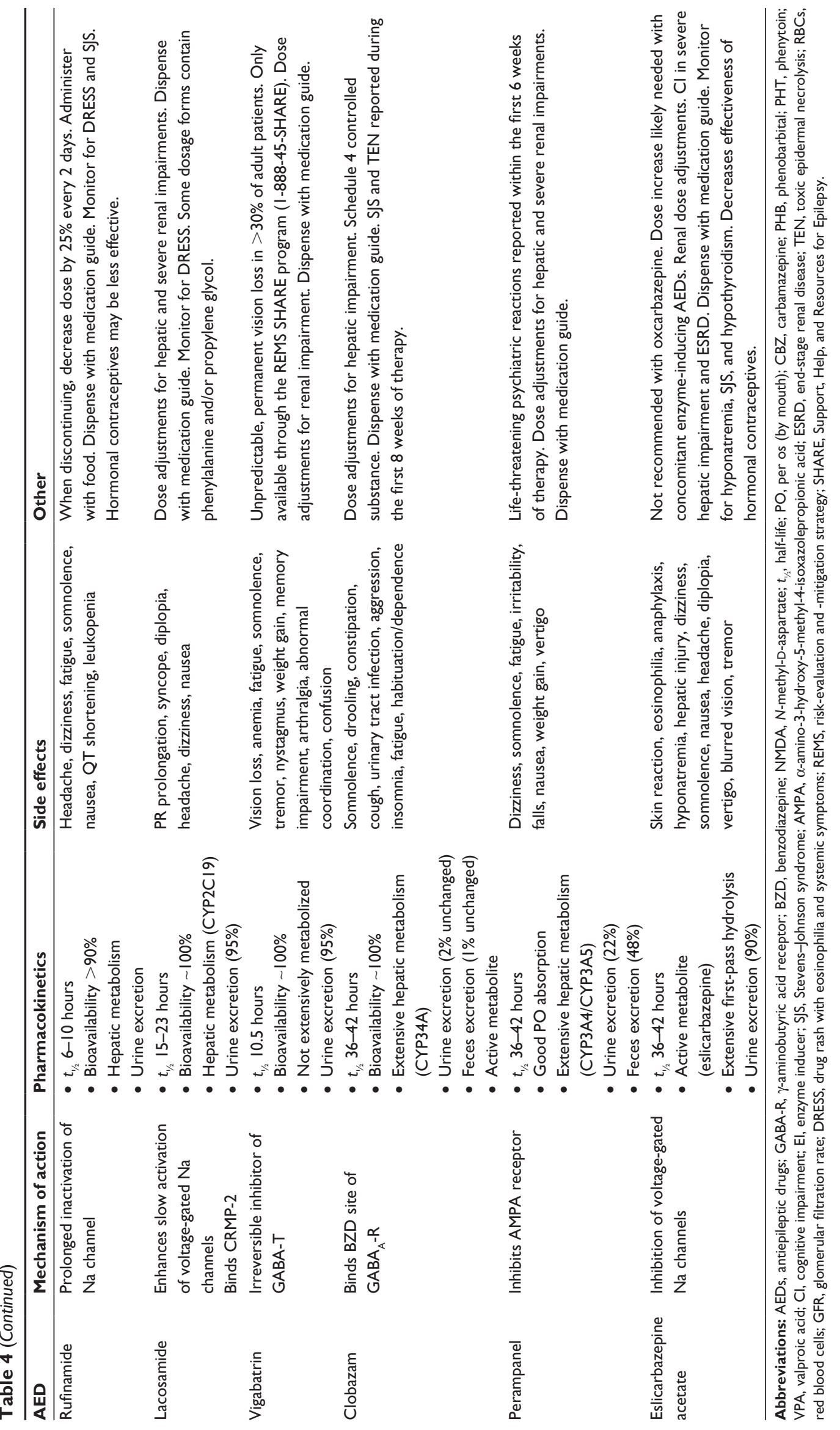


Table 5 AED interactions with other drug classes

\begin{tabular}{|c|c|c|c|c|c|c|c|c|c|c|c|c|c|c|c|}
\hline & \multicolumn{3}{|c|}{ Enzyme inducers } & \multirow[t]{2}{*}{ VPA } & \multirow[t]{2}{*}{ LTG } & \multirow[t]{2}{*}{ ZNG } & \multirow[t]{2}{*}{ ETX } & \multirow[t]{2}{*}{ CLZ } & \multirow[t]{2}{*}{ CLB } & \multirow[t]{2}{*}{$\mathbf{O X Z}$} & \multirow[t]{2}{*}{ TPM } & \multirow[t]{2}{*}{ FLB } & \multirow[t]{2}{*}{ TIG } & \multirow[t]{2}{*}{ LEV } & \multirow[t]{2}{*}{ LAC } \\
\hline & PHT & CBZ & PHB & & & & & & & & & & & & \\
\hline \multicolumn{16}{|l|}{ Anticoagulants } \\
\hline Apixaban & $\otimes \downarrow$ & $\otimes \downarrow$ & - & - & - & - & - & - & - & - & - & - & - & - & - \\
\hline Dabigatran & $\downarrow$ & $\downarrow$ & $\downarrow$ & - & - & - & - & - & - & - & - & - & - & - & - \\
\hline Edoxaban & $\downarrow$ & $\downarrow$ & $\downarrow$ & - & - & - & - & - & - & - & - & - & - & - & - \\
\hline Rivaroxaban & $\downarrow$ & $\downarrow$ & - & - & - & - & - & - & - & - & - & - & - & - & - \\
\hline Warfarin & $\downarrow * \uparrow$ & $\downarrow$ & $\downarrow$ & $\uparrow$ & - & - & - & - & - & $\downarrow / \uparrow$ & $\downarrow$ & $\uparrow$ & - & - & - \\
\hline \multicolumn{16}{|c|}{ Typical antipsychotics } \\
\hline Droperidol & - & - & $\mathrm{S}$ & - & - & - & - & $\mathrm{S}$ & $S$ & $\mathrm{~S}$ & - & - & - & - & - \\
\hline Haloperidol & - & $\downarrow$ & $\mathrm{S}$ & - & - & - & - & $\mathrm{S}$ & $\uparrow$ & - & $\mathrm{S}$ & - & - & - & - \\
\hline Trifluoperazine & - & - & $\mathrm{S}$ & - & - & - & - & $\mathrm{S}$ & - & - & $S$ & - & - & - & - \\
\hline \multicolumn{16}{|c|}{ Atypical antipsychotics } \\
\hline Aripiprazole & $\downarrow$ & $\downarrow$ & $\downarrow S$ & - & - & - & - & $S$ & $\uparrow S$ & $\downarrow$ & $\downarrow S$ & - & - & - & - \\
\hline Asenapine & - & $\downarrow$ & $\downarrow$ & - & - & - & - & - & $S$ & - & - & - & - & - & - \\
\hline Clozapine & $\downarrow$ & $\otimes \downarrow$ & $\downarrow S$ & $\downarrow$ & - & - & - & $S$ & $S$ & $\downarrow$ & $\downarrow S$ & - & - & - & - \\
\hline Lurasidone & $\otimes \downarrow S$ & $\otimes \downarrow S$ & $\otimes \downarrow S$ & - & $\mathrm{S}$ & $S$ & $S$ & $S$ & - & $\otimes \downarrow$ & $S$ & $S$ & $S$ & $S$ & - \\
\hline Olanzapine & - & $\downarrow$ & $\downarrow S$ & - & - & - & - & $S$ & $S$ & - & $S$ & - & - & - & - \\
\hline Paliperidone & $\downarrow$ & $\downarrow$ & $\downarrow S$ & - & - & - & - & $S$ & $S$ & - & $S$ & - & - & - & - \\
\hline Quetiapine & $\downarrow$ & $\downarrow * \uparrow$ & $\downarrow S$ & - & - & - & - & $S$ & $S$ & $\downarrow$ & $\downarrow S$ & - & - & - & - \\
\hline \multicolumn{16}{|l|}{ SSRIs } \\
\hline Citalopram & - & $\downarrow$ & - & - & $\mathrm{S}$ & - & - & - & - & - & - & - & - & - & - \\
\hline Paroxetine & - & - & - & - & $S$ & - & - & - & $\uparrow$ & - & - & - & - & - & - \\
\hline Fluoxetine & $* \uparrow$ & $* \uparrow$ & - & - & $\mathrm{S}$ & - & - & - & $\uparrow$ & - & - & - & - & - & - \\
\hline Sertraline & $\uparrow$ & $* \uparrow$ & - & - & $S$ & - & - & - & $\uparrow$ & - & - & - & - & - & - \\
\hline \multicolumn{16}{|l|}{ SNRIs } \\
\hline Duloxetine & - & $\downarrow$ & $\downarrow$ & - & - & - & - & - & $\uparrow$ & - & - & - & - & - & - \\
\hline Venlafaxine & - & - & - & - & - & - & - & - & $\uparrow$ & - & - & - & - & - & - \\
\hline \multicolumn{16}{|l|}{ TCAs } \\
\hline Amitriptyline & $\downarrow * \uparrow$ & $\downarrow$ & $\downarrow S$ & - & - & - & - & $\mathrm{S}$ & $\uparrow S$ & $\uparrow$ & $\downarrow S$ & $\uparrow$ & - & - & - \\
\hline Nortriptyline & $\downarrow$ & $\downarrow$ & $\downarrow S$ & - & - & - & - & $S$ & $\uparrow S$ & - & $S$ & - & - & - & - \\
\hline \multicolumn{16}{|l|}{ MAOIs } \\
\hline Phenelzine & - & $\otimes$ & $* \uparrow$ & - & - & - & - & - & - & - & - & - & - & - & - \\
\hline \multicolumn{16}{|c|}{ Other antidepressants } \\
\hline Bupropion & - & $\downarrow$ & $\downarrow$ & - & - & - & - & - & - & - & - & - & - & - & - \\
\hline Mirtazapine & - & - & $S$ & - & - & - & - & $S$ & $\uparrow S$ & - & $S$ & - & - & - & - \\
\hline
\end{tabular}

Notes: $\downarrow$, AED causes decrease in medication level/efficacy; $\uparrow$, AED causes increase in medication level/efficacy; * $\downarrow / * \uparrow$, medication causes decrease or increase in AED level/ efficacy; $\otimes$, combination contraindicated; S, increased CNS depression; $\downarrow / \uparrow$, OXZ decreases warfarin by CYP34A but increases it by CYP2CI9.

Abbreviations: AED, antiepileptic drug; PHT, phenytoin; CBZ, carbamazepine; PHB, phenobarbital; VPA, valproic acid; LTG, lamotrigine; ZNG, zonisamide; ETX, ethosuximide; CLZ, clonazepam; CLB, clobazam; OXZ, oxcarbazepine; TPM, topiramate; FLB, felbamate; TIG, tiagabine; LEV, levetiracetam; LAC, lacosamide; SSRIs, selective serotonin-reuptake inhibitors; SNRIs, selective serotonin-norepinephrine reuptake inhibitors; TCAs, tricyclic antidepressants; MAOls, monoamine oxidase inhibitors; CNS, central nervous system.

avenues for new research that would help practitioners optimize epilepsy management.

\section{Disclosure}

GMB serves on the UCB Speaker's Bureau. The other authors report no conflicts of interest in this work.

\section{References}

1. Centers for Disease Control and Prevention. Epilepsy fast facts. 2015. Available from: cdc.gov/epilepsy/basics/fast-facts.htm. Accessed October 8, 2015.

2. Sirven JI, Noe K, Hoerth M, Drazkowski J. Antiepileptic drugs 2012: recent advances and trends. Mayo Clin Proc. 2012;87(9):879-889.
3. Kelly TE. Teratogenicity of anticonvulsant drugs. I: Review of the literature. Am J Med Genet. 1984;19(3):413-434.

4. Olafsson E, Hallgrimsson JT, Hauser WA, Ludvigsson P, Gudmundsson G. Pregnancies of women with epilepsy: a population-based study in Iceland. Epilepsia. 1998;39(8):887-892.

5. Adab N, Kini U, Vinten J, et al. The longer term outcome of children born to mothers with epilepsy. J Neurol Neurosurg Psychiatry. 2004; 75(11):1575-1583.

6. Barrett C, Richens A. Epilepsy and pregnancy: report of an epilepsy research foundation workshop. Epilepsy Res. 2003;52(3):147-187.

7. Tomson T, Battino D, Bonizzoni E, et al. Dose-dependent risk of malformations with antiepileptic drugs: an analysis of data from the EURAP epilepsy and pregnancy registry. Lancet Neurol. 2011;10(7): 609-617.

8. Vajda FJ, O'Brien TJ, Graham J, Lander CM, Eadie MJ. The outcomes of pregnancy in women with untreated epilepsy. Seizure. 2015;24: $77-81$. 
9. Pennell PB, Peng L, Newport DJ, et al. Lamotrigine in pregnancy: clearance, therapeutic drug monitoring, and seizure frequency. Neurology. 2008;70(22 Pt 2):2130-2136.

10. Petrenaite V, Sabers A, Hansen-Schwartz J. Seizure deterioration in women treated with oxcarbazepine during pregnancy. Epilepsy Res. 2009;84(2-3):245-249.

11. Harden CL, Pennell PB, Koppel BS, et al. Practice parameter update: management issues for women with epilepsy - focus on pregnancy (an evidence-based review): vitamin K, folic acid, blood levels, and breastfeeding. Report of the Quality Standards Subcommittee and Therapeutics and Technology Assessment Subcommittee of the American Academy of Neurology and American Epilepsy Society. Neurology. 2009;73(2):142-149.

12. Tomson T, Landmark CJ, Battino D. Antiepileptic drug treatment in pregnancy: changes in drug disposition and their clinical implications. Epilepsia. 2013;54(3):405-414.

13. Reisinger TL, Newman M, Loring DW, Pennell PB, Meador KJ. Antiepileptic drug clearance and seizure frequency during pregnancy in women with epilepsy. Epilepsy Behav. 2013;29(1):13-18.

14. Burakgazi E, Pollard J, Harden C. The effect of pregnancy on seizure control and antiepileptic drugs in women with epilepsy. Rev Neurol Dis. 2011;8(1-2):16-22.

15. Battino D, Tomson T, Bonizzoni E, et al. Seizure control and treatment changes in pregnancy: observations from the EURAP epilepsy pregnancy registry. Epilepsia. 2013;54(9):1621-1627.

16. Thomas SV, Syam U, Devi JS. Predictors of seizures during pregnancy in women with epilepsy. Epilepsia. 2012;53(5):e85-e88.

17. Harden CL, Hopp J, Ting TY, et al. Management issues for women with epilepsy - focus on pregnancy (an evidence-based review): I. Obstetrical complications and change in seizure frequency. Epilepsia. 2009;50(5): 1229-1236.

18. Hiilesmaa VK, Bardy A, Teramo K. Obstetric outcome in women with epilepsy. Am J Obstet Gynecol. 1985;152(5):499-504.

19. Viinikainen K, Heinonen S, Eriksson K, Kälviäinen R. Community-based, prospective, controlled study of obstetric and neonatal outcome of 179 pregnancies in women with epilepsy. Epilepsia. 2006;47(1):186-192.

20. Hvas CL, Henriksen TB, Østergaard JR, Dam M. Epilepsy and pregnancy: effect of antiepileptic drugs and lifestyle on birthweight. BJOG. 2000;107(7):896-902.

21. Sukumaran SC, Sarma PS, Thomas SV. Polytherapy increases the risk of infertility in women with epilepsy. Neurology. 2010;75(15): 1351-1355.

22. Edlow JA, Caplan LR, O'Brien K, Tibbles CD. Diagnosis of acute neurological emergencies in pregnant and post-partum women. Lancet Neurol. 2013;12(2):175-185.

23. Karnad DR, Guntupalli KK. Neurologic disorders in pregnancy. Crit Care Med. 2005;33(10 Suppl):S362-S371.

24. Wallis AB, Saftlas AF, Hsia J, Atrash HK. Secular trends in the rates of preeclampsia, eclampsia, and gestational hypertension, united states, 1987-2004. Am J Hypertens. 2008;21(5):521-526.

25. Maynard SE, Karumanchi SA. Angiogenic factors and preeclampsia. Semin Nephrol. 2011;31(1):33-46.

26. Schroeder BM. ACOG practice bulletin on diagnosing and managing preeclampsia and eclampsia. American College of Obstetricians and Gynecologists. Am Fam Physician. 2002;66(2):330-331.

27. Decollogne S, Tomas A, Lecerf C, Adamowicz E, Seman M. NMDA receptor complex blockade by oral administration of magnesium: comparison with MK-801. Pharmacol Biochem Behav. 1997; 58(1):261-268.

28. [No authors listed]. Which anticonvulsant for women with eclampsia? Evidence from the collaborative eclampsia trial. Lancet. 1995;345(8963): 1455-1463.

29. Committee on Obstetric Practice. Committee opinion no. 514: emergent therapy for acute-onset, severe hypertension with preeclampsia or eclampsia. Obstet Gynecol. 2011;118(6):1465-1468.

30. Thomas SV. Managing epilepsy in pregnancy. Neurol India. 2011;59(1): 59-65.
31. Sibai BM. Diagnosis, prevention, and management of eclampsia. Obstet Gynecol. 2005;105(2):402-410.

32. Hart LA, Sibai BM. Seizures in pregnancy: epilepsy, eclampsia, and stroke. Semin Perinatol. 2013;37(4):207-224.

33. Varner M. Seizures and status epilepticus. In: Belfort M, Saade G, Foley M, Phelan J, Dildy G, editors. Critical Care Obstetrics. 5th ed. Oxford, UK: Wiley-Blackwell; 2010:222-227.

34. Pennell PB. Pregnancy in women who have epilepsy. Neurol Clin. 2004;22(4):799-820.

35. Betts T, Fox C. Proactive pre-conception counselling for women with epilepsy - is it effective? Seizure. 1999;8(6):322-327.

36. Oguni M, Dansky L, Andermann E, Sherwin A, Andermann F. Improved pregnancy outcome in epileptic women in the last decade: relationship to maternal anticonvulsant therapy. Brain Dev. 1992;14(6):371-380.

37. Martin PJ, Millac PA. Pregnancy, epilepsy, management and outcome: a 10-year perspective. Seizure. 1993;2(4):277-280.

38. Metcalfe A, Stewart C, Postans N, et al. Abnormal loading of the major joints in knee osteoarthritis and the response to knee replacement. Gait Posture. 2013;37(1):32-36.

39. Pack AM, Davis AR, Kritzer J, Yoon A, Camus A. Antiepileptic drugs: are women aware of interactions with oral contraceptives and potential teratogenicity? Epilepsy Behav. 2009;14(4):640-644.

40. Pashley S, O'Donoghue MF. The safety of anti-epileptic drug regimens: a qualitative study of factors determining the success of counselling women before conception. J Fam Plann Reprod Health Care. 2009;35(3): $153-156$.

41. Birbeck GL, French JA, Perucca E, et al. Evidence-based guideline: antiepileptic drug selection for people with HIV/AIDS. Report of the Quality Standards Subcommittee of the American Academy of Neurology and the Ad Hoc Task Force of the Commission on Therapeutic Strategies of the International League Against Epilepsy. Neurology. 2012; 78(2):139-145

42. Okulicz JF, Grandits GA, French JA, et al. The impact of enzymeinducing antiepileptic drugs on antiretroviral drug levels: a case-control study. Epilepsy Res. 2013;103(2-3):245-253.

43. Siddiqi O, Birbeck GL. Safe treatment of seizures in the setting of HIV/ AIDS. Curr Treat Options Neurol. 2013;15(4):529-543.

44. Yacoob Y, Bhigjee AI, Moodley P, Parboosing R. Sodium valproate and highly active antiretroviral therapy in HIV positive patients who develop new onset seizures. Seizure. 2011;20(1):80-82.

45. Brew BJ, Thompson J. Epilepsy: issues with antiepileptic drug use in HIV-infected patients. Nat Rev Neurol. 2012;8(4):187-188.

46. Lee K, Vivithanaporn P, Siemieniuk RA, et al. Clinical outcomes and immune benefits of anti-epileptic drug therapy in HIV/AIDS. BMC Neurol. 2010;10:44.

47. Siddiqi OK, Elafros MA, Sikazwe I, et al. Acute EEG findings in HIV-infected Zambian adults with new-onset seizure. Neurology. 2015;84(13):1317-1322.

48. Potchen MJ, Siddiqi OK, Elafros MA, et al. Neuroimaging abnormalities and seizure recurrence in a prospective cohort study of Zambians with human immunodeficiency virus and first seizure. Neurol Int. 2014;6(4):5547.

49. Sikazwe I, Elafros MA, Bositis CM, et al. HIV and new onset seizures: slipping through the cracks in HIV care and treatment. HIV Med. Epub 2015 Jul 22.

50. Corrada MM, Brookmeyer R, Paganini-Hill A, Berlau D, Kawas CH. Dementia incidence continues to increase with age in the oldest old: the 90+ study. Ann Neurol. 2010;67(1):114-121.

51. Ghosh S, Jehi LE. New-onset epilepsy in the elderly: challenges for the internist. Cleve Clin J Med. 2014;81(8):490-498.

52. Hauser WA, Annegers JF, Kurland LT. Incidence of epilepsy and unprovoked seizures in Rochester, Minnesota: 1935-1984. Epilepsia. 1993;34(3):453-468.

53. Friedman D, Honig LS, Scarmeas N. Seizures and epilepsy in Alzheimer's disease. CNS Neurosci Ther. 2012;18(4):285-294.

54. Hesdorffer DC, Hauser WA, Annegers JF, Kokmen E, Rocca WA. Dementia and adult-onset unprovoked seizures. Neurology. 1996;46(3): 727-730. 
55. Picco A, Archetti S, Ferrara M, et al. Seizures can precede cognitive symptoms in late-onset Alzheimer's disease. J Alzheimers Dis. 2011; 27(4):737-742.

56. Vossel KA, Beagle AJ, Rabinovici GD, et al. Seizures and epileptiform activity in the early stages of Alzheimer disease. JAMA Neurol. 2013;70(9):1158-1166.

57. Romanelli MF, Morris JC, Ashkin K, Coben LA. Advanced Alzheimer's disease is a risk factor for late-onset seizures. Arch Neurol. 1990;47(8): $847-850$.

58. Noebels J. A perfect storm: converging paths of epilepsy and Alzheimer's dementia intersect in the hippocampal formation. Epilepsia. 2011; 52 Suppl 1:39-46.

59. McAreavey MJ, Ballinger BR, Fenton GW. Epileptic seizures in elderly patients with dementia. Epilepsia. 1992;33(4):657-660.

60. Laccheo I, Ablah E, Heinrichs R, Sadler T, Baade L, Liow K. Assessment of quality of life among the elderly with epilepsy. Epilepsy Behav. 2008;12(2):257-261.

61. Theodore WH. The postictal state: effects of age and underlying brain dysfunction. Epilepsy Behav. 2010;19(2):118-120.

62. Hayes MJ, Langman MJ, Short AH. Changes in drug metabolism with increasing age: 2 . Phenytoin clearance and protein binding. Br J Clin Pharmacol. 1975;2(1):73-79.

63. Birnbaum A, Hardie NA, Leppik IE, et al. Variability of total phenytoin serum concentrations within elderly nursing home residents. Neurology. 2003;60(4):555-559.

64. Rowan AJ, Ramsay RE, Collins JF, et al. New onset geriatric epilepsy: a randomized study of gabapentin, lamotrigine, and carbamazepine. Neurology. 2005;64(11):1868-1873.

65. Brodie MJ, Overstall PW, Giorgi L. Multicentre, double-blind, randomised comparison between lamotrigine and carbamazepine in elderly patients with newly diagnosed epilepsy. The UK Lamotrigine Elderly Study Group. Epilepsy Res. 1999;37(1):81-87.

66. Cumbo E, Ligori LD. Levetiracetam, lamotrigine, and phenobarbital in patients with epileptic seizures and Alzheimer's disease. Epilepsy Behav. 2010;17(4):461-466.

67. Borhani Haghighi A, Sabayan B. Can prolonged administration of valproic acid put patients with epilepsy at higher risk for development of Alzheimer's disease? Epilepsy Behav. 2008;12(1):206-207.

68. Tekin S, Aykut-Bingöl C, Tanridağ T, Aktan S. Antiglutamatergic therapy in Alzheimer's disease - effects of lamotrigine. short communication. J Neural Transm (Vienna). 1998;105(2-3):295-303.

69. Mendez M, Lim G. Seizures in elderly patients with dementia: epidemiology and management. Drugs Aging. 2003;20(11):791-803.

70. Johnston JA, Lineberry CG, Ascher JA, et al. A 102-center prospective study of seizure in association with bupropion. J Clin Psychiatry. 1991;52(11):450-456.

71. Williams AM, Park SH. Seizure associated with clozapine:incidence, etiology, and management. CNS Drugs. 2015;29(2):101-111.

72. Alper K, Schwartz KA, Kolts RL, Khan A. Seizure incidence in psychopharmacological clinical trials: an analysis of Food and Drug Administration (FDA) summary basis of approval reports. Biol Psychiatry. 2007;62(4):345-354.

73. Kumlien E, Lundberg PO. Seizure risk associated with neuroactive drugs: data from the WHO adverse drug reactions database. Seizure. 2010;19(2):69-73.

74. Lertxundi U, Hernandez R, Medrano J, Domingo-Echaburu S, García M, Aguirre C. Antipsychotics and seizures: higher risk with atypicals? Seizure. 2013;22(2):141-143.

75. Bloechliger M, Rüegg S, Jick SS, Meier CR, Bodmer M. Antipsychotic drug use and the risk of seizures: follow-up study with a nested casecontrol analysis. CNS Drugs. 2015;29(7):591-603.

76. Abend NS, Dlugos DJ, Hahn CD, Hirsch LJ, Herman ST. Use of EEG monitoring and management of non-convulsive seizures in critically ill patients: a survey of neurologists. Neurocrit Care. 2010; 12(3):382-389.

77. Gavvala J, Abend N, LaRoche S, et al. Continuous EEG monitoring: a survey of neurophysiologists and neurointensivists. Epilepsia. 2014;55(11):1864-1871.
78. Hirsch LJ. Urgent continuous EEG (cEEG) monitoring leads to changes in treatment in half of cases. Epilepsy Curr. 2010;10(4):82-85.

79. Brophy GM, Bell R, Claassen J, et al. Guidelines for the evaluation and management of status epilepticus. Neurocrit Care. 2012;17(1):3-23.

80. Foreman B, Claassen J, Abou Khaled K, et al. Generalized periodic discharges in the critically ill: a case-control study of 200 patients. Neurology. 2012;79(19):1951-1960.

81. Oddo M, Carrera E, Claassen J, Mayer SA, Hirsch LJ. Continuous electroencephalography in the medical intensive care unit. Crit Care Med. 2009;37(6):2051-2056.

82. Abend NS, Gutierrez-Colina A, Zhao H, et al. Interobserver reproducibility of electroencephalogram interpretation in critically ill children. J Clin Neurophysiol. 2011;28(1):15-19.

83. Beniczky S, Hirsch LJ, Kaplan PW, et al. Unified EEG terminology and criteria for nonconvulsive status epilepticus. Epilepsia. 2013;54 Suppl 6:28-29.

84. Stewart CP, Otsubo H, Ochi A, Sharma R, Hutchison JS, Hahn CD Seizure identification in the ICU using quantitative EEG displays. Neurology. 2010;75(17):1501-1508.

85. Yigit O, Eray O, Mihci E, Yilmaz D, Eray B, Ozkaynak S. EEG as a part of the decision-making process in the emergency department. Eur J Emerg Med. 2013;20(6):402-407.

86. Hauf M, Slotboom J, Nirkko A, von Bredow F, Ozdoba C, Wiest R. Cortical regional hyperperfusion in nonconvulsive status epilepticus measured by dynamic brain perfusion CT. AJNR Am J Neuroradiol. 2009;30(4):693-698.

87. Merceron S, Geeraerts T, Montlahuc C, Bedos J, Resche-Rigon M, Legriel S. Assessment of cerebral blood flow changes in nonconvulsive status epilepticus in comatose patients: a pathophysiological transcranial Doppler study. Seizure. 2014;23(4):284-289.

88. Wijdicks EF, Hijdra A, Young GB, Bassetti CL, Wiebe S. Practice parameter: prediction of outcome in comatose survivors after cardiopulmonary resuscitation (an evidence-based review). Report of the Quality Standards Subcommittee of the American Academy Of Neurology. Neurology. 2006;67(2):203-210.

89. Peberdy MA, Callaway CW, Neumar RW, et al. Part 9: Post-cardiac arrest care: 2010 American Heart Association guidelines for cardiopulmonary resuscitation and emergency cardiovascular care. Circulation. 2010;122(18 Suppl 3):S768-S786.

90. Knight WA, Hart KW, Adeoye OM, et al. The incidence of seizures in patients undergoing therapeutic hypothermia after resuscitation from cardiac arrest. Epilepsy Res. 2013;106(3):396-402.

91. Rittenberger JC, Popescu A, Brenner RP, Guyette FX, Callaway CW. Frequency and timing of nonconvulsive status epilepticus in comatose post-cardiac arrest subjects treated with hypothermia. Neurocrit Care. 2012;16(1):114-122.

92. Sandroni C, Nolan JP. Neurologically favorable outcome is still possible despite myoclonus in comatose survivors of cardiac arrest. Crit Care Med. 2015;43(9):e396-e397.

93. Accardo J, De Lisi D, Lazzerini P, Primavera A. Good functional outcome after prolonged postanoxic comatose myoclonic status epilepticus in a patient who had undergone bone marrow transplantation. Case Rep Neurol Med. 2013;2013:872127.

94. Malhotra S, Mohinder K. Lance-Adams syndrome: difficulties surrounding diagnosis, prognostication, and treatment after cardiac arrest. Anesth Essays Res. 2012;6(2):218-222.

95. Crepeau AZ, Britton JW, Fugate JE, Rabinstein AA, Wijdicks EF. Electroencephalography in survivors of cardiac arrest: comparing preand post-therapeutic hypothermia eras. Neurocrit Care. 2015;22(1): $165-172$.

96. Dragancea I, Backman S, Westhall E, Rundgren M, Friberg H, Cronberg T. Outcome following postanoxic status epilepticus in patients with targeted temperature management after cardiac arrest. Epilepsy Behav. 2015;49:173-177.

97. Sadaka F, Doerr D, Hindia J, Lee KP, Logan W. Continuous electroencephalogram in comatose postcardiac arrest syndrome patients treated with therapeutic hypothermia: outcome prediction study. $J$ Intensive Care Med. 2015;30(5):292-296. 
98. Maia B, Roque R, Amaral-Silva A, Lourenço S, Bento L, Alcântara J. Predicting outcome after cardiopulmonary arrest in therapeutic hypothermia patients: clinical, electrophysiological and imaging prognosticators. Acta Med Port. 2013;26(2):93-97.

99. Karapetkova M, Koenig MA, Jia X. Early prognostication markers in cardiac arrest patients treated with hypothermia. Eur J Neurol. Epub 2015 Jul 31.

100. Sandroni C, Geocadin RG. Neurological prognostication after cardiac arrest. Curr Opin Crit Care. 2015;21(3):209-214.

101. Abend NS, Topjian A, Ichord R, et al. Electroencephalographic monitoring during hypothermia after pediatric cardiac arrest. Neurology. 2009;72(22):1931-1940.

102. Cronberg T, Brizzi M, Liedholm LJ, et al. Neurological prognostication after cardiac arrest - recommendations from the Swedish Resuscitation Council. Resuscitation. 2013;84(7):867-872.

103. Tjepkema-Cloostermans MC, Hofmeijer J, Trof RJ, Blans MJ, Beishuizen A, van Putten MJ. Electroencephalogram predicts outcome in patients with postanoxic coma during mild therapeutic hypothermia. Crit Care Med. 2015;43(1):159-167.

104. Mani R, Schmitt SE, Mazer M, Putt ME, Gaieski DF. The frequency and timing of epileptiform activity on continuous electroencephalogram in comatose post-cardiac arrest syndrome patients treated with therapeutic hypothermia. Resuscitation. 2012;83(7):840-847.

105. Amorim E, Rittenberger JC, Baldwin ME, Callaway CW, Popescu A. Malignant EEG patterns in cardiac arrest patients treated with targeted temperature management who survive to hospital discharge. Resuscitation. 2015;90:127-132.

106. Alvarez V, Oddo M, Rossetti AO. Stimulus-induced rhythmic, periodic or ictal discharges (SIRPIDs) in comatose survivors of cardiac arrest: characteristics and prognostic value. Clin Neurophysiol. 2013; 124(1):204-208.

107. Rossetti AO, Urbano LA, Delodder F, Kaplan PW, Oddo M. Prognostic value of continuous EEG monitoring during therapeutic hypothermia after cardiac arrest. Crit Care. 2010;14(5):R173.

108. Rundgren M, Westhall E, Cronberg T, Rosen I, Friberg H. Continuous amplitude-integrated electroencephalogram predicts outcome in hypothermia-treated cardiac arrest patients. Crit Care Med. 2010; 38(9):1838-1844.

109. Burjek NE, Wagner CE, Hollenbeck RD, et al. Early bispectral index and sedation requirements during therapeutic hypothermia predict neurologic recovery following cardiac arrest. Crit Care Med. 2014; 42(5):1204-1212.

110. Riker RR, Stone PC Jr, May T, McCrum B, Fraser GL, Seder D. Initial bispectral index may identify patients who will awaken during therapeutic hypothermia after cardiac arrest: a retrospective pilot study. Resuscitation. 2013;84(6):794-797.

111. Mohammed HS. Hypothermia mitigates neurochemical alterations in rat's cerebral cortex during status epilepticus induced by pilocarpine. Gen Physiol Biophys. Epub 2015 Jul 29.

112. Kowski AB, Kanaan H, Schmitt FC, Holtkamp M. Deep hypothermia terminates status epilepticus - an experimental study. Brain Res. 2012; 1446:119-126.

113. Wang Y, Liu PP, Li LY, Zhang HM, Li T. Hypothermia reduces brain edema, spontaneous recurrent seizure attack, and learning memory deficits in the kainic acid treated rats. CNS Neurosci Ther. 2011;17(5):271-280.

114. Yu L, Zhou Y, Chen W, Wang Y. Mild hypothermia pretreatment protects against pilocarpine-induced status epilepticus and neuronal apoptosis in immature rats. Neuropathology. 2011;31(2):144-151.

115. Marchi NA, Novy J, Faouzi M, Stahli C, Burnand B, Rossetti AO. Status epilepticus: impact of therapeutic coma on outcome. Crit Care Med. 2015;43(5):1003-1009.

116. Zeiler FA, Zeiler KJ, Teitelbaum J, Gillman LM, West M. Therapeutic hypothermia for refractory status epilepticus. Can J Neurol Sci. 2015;42(4):221-229.

117. Yang $X$, Wang X. Potential mechanisms and clinical applications of mild hypothermia and electroconvulsive therapy on refractory status epilepticus. Expert Rev Neurother. 2015;15(2):135-144.
118. Crepeau AZ, Fugate JE, Mandrekar J, et al. Value analysis of continuous EEG in patients during therapeutic hypothermia after cardiac arrest. Resuscitation. 2014;85(6):785-789.

119. Alvarez V, Sierra-Marcos A, Oddo M, Rossetti AO. Yield of intermittent versus continuous EEG in comatose survivors of cardiac arrest treated with hypothermia. Crit Care. 2013;17(5):R190.

120. Acton EK, Tatum WO. Inpatient psychiatric consultation for newlydiagnosed patients with psychogenic non-epileptic seizures. Epilepsy Behav. 2013;27(1):36-39.

121. Pintor L, Bailles E, Matrai S, et al. Efficiency of venlafaxine in patients with psychogenic nonepileptic seizures and anxiety and/or depressive disorders. J Neuropsychiatry Clin Neurosci. 2010;22(4):401-408.

122. LaFrance WC Jr, Baker GA, Duncan R, Goldstein LH, Reuber M. Minimum requirements for the diagnosis of psychogenic nonepileptic seizures: a staged approach. A report from the International League Against Epilepsy Nonepileptic Seizures Task Force. Epilepsia. 2013; 54(11):2005-2018.

123. Arthuis M, Micoulaud-Franchi JA, Bartolomei F, McGonigal A, Guedj E. Resting cortical PET metabolic changes in psychogenic non-epileptic seizures (PNES). J Neurol Neurosurg Psychiatry. 2014; 86(10):1106-1112.

124. Lee S, Allendorfer JB, Gaston TE, et al. White matter diffusion abnormalities in patients with psychogenic non-epileptic seizures. Brain Res. 2015;1620:169-176.

125. Xue Q, Wang ZY, Xiong XC, Tian CY, Wang YP, Xu P. Altered brain connectivity in patients with psychogenic non-epileptic seizures: a scalp electroencephalography study. J Int Med Res. 2013;41(5):1682-1690.

126. Reinsberger C, Sarkis R, Papadelis C, et al. Autonomic changes in psychogenic nonepileptic seizures: toward a potential diagnostic biomarker? Clin EEG Neurosci. 2015;46(1):16-25.

127. Moseley BD, Dewar S, Haneef Z, Stern JM. How long is long enough? The utility of prolonged inpatient video EEG monitoring. Epilepsy Res. 2015;109:9-12.

128. Popkirov S, Grönheit W, Wellmer J. Hyperventilation and photic stimulation are useful additions to a placebo-based suggestive seizure induction protocol in patients with psychogenic nonepileptic seizures. Epilepsy Behav. 2015;46:88-90.

129. Goyal G, Kalita J, Misra UK. Utility of different seizure induction protocols in psychogenic nonepileptic seizures. Epilepsy Res. 2014; 108(6):1120-1127.

130. Robles L, Chiang S, Haneef Z. Review-of-systems questionnaire as a predictive tool for psychogenic nonepileptic seizures. Epilepsy Behav. 2015;45:151-154.

131. Gubbi J, Kusmakar S, Rao A, Yan B, O’Brien T, Palaniswami M. Automatic detection and classification of convulsive psychogenic non-epileptic seizures using a wearable device. IEEE J Biomed Health Inform. Epub 2015 Jun 17.

132. Beniczky S, Conradsen I, Moldovan M, et al. Automated differentiation between epileptic and nonepileptic convulsive seizures. Ann Neurol. 2015;77(2):348-351.

133. Ristić AJ, Drašković M, Bukumirić Z, Sokić D. Reliability of the witness descriptions of epileptic seizures and psychogenic non-epileptic attacks: a comparative analysis. Neurol Res. 2015;37(6):560-562.

134. Alessi R, Valente KD. Psychogenic nonepileptic seizures: should we use response to AEDS as a red flag for the diagnosis? Seizure. 2014;23(10):906-908.

135. Asadi-Pooya AA, Sperling MR. Epidemiology of psychogenic nonepileptic seizures. Epilepsy Behav. 2015;46:60-65.

136. Duncan R, Razvi S, Mulhern S. Newly presenting psychogenic nonepileptic seizures: incidence, population characteristics, and early outcome from a prospective audit of a first seizure clinic. Epilepsy Behav. 2011;20(2):308-311.

137. LaFrance WC Jr, Miller IW, Ryan CE, et al. Cognitive behavioral therapy for psychogenic nonepileptic seizures. Epilepsy Behav. 2009;14(4):591-596.

138. Goldstein LH, Chalder T, Chigwedere C, et al. Cognitive-behavioral therapy for psychogenic nonepileptic seizures: a pilot RCT. Neurology. 2010;74(24):1986-1994. 
139. Santos NO, Benute GR, Santiago A, Marchiori PE, Lucia MC. Psychogenic non-epileptic seizures and psychoanalytical treatment: results. Rev Assoc Med Bras. 2014;60(6):577-584.

140. Baslet G, Dworetzky B, Perez DL, Oser M. Treatment of psychogenic nonepileptic seizures: updated review and findings from a mindfulnessbased intervention case series. Clin EEG Neurosci. 2015;46(1): 54-64.

141. LaFrance WC Jr, Keitner GI, Papandonatos GD, et al. Pilot pharmacologic randomized controlled trial for psychogenic nonepileptic seizures. Neurology. 2010;75(13):1166-1173.

142. LaFrance WC Jr, Baird GL, Barry JJ, et al. Multicenter pilot treatment trial for psychogenic nonepileptic seizures: a randomized clinical trial. JAMA Psychiatry. 2014;71(9):997-1005.

143. McKenzie P, Oto M, Russell A, Pelosi A, Duncan R. Early outcomes and predictors in 260 patients with psychogenic nonepileptic attacks. Neurology. 2010;74(1):64-69.

144. Sadan O, Neufeld MY, Parmet Y, Rozenberg A, Kipervasser S. Psychogenic seizures: long-term outcome in patients with and without epilepsy. Acta Neurol Scand. Epub 2015 Jul 14.

145. Mayor R, Brown RJ, Cock H, et al. A feasibility study of a brief psycho-educational intervention for psychogenic nonepileptic seizures. Seizure. 2013;22(9):760-765.

146. Razvi S, Mulhern S, Duncan R. Newly diagnosed psychogenic nonepileptic seizures: health care demand prior to and following diagnosis at a first seizure clinic. Epilepsy Behav. 2012;23(1):7-9.

147. Dworetzky BA, Weisholtz DS, Perez DL, Baslet G. A clinically oriented perspective on psychogenic nonepileptic seizure-related emergencies. Clin EEG Neurosci. 2015;46(1):26-33.

148. Asadi-Pooya AA, Emami M, Emami Y. Ictal injury in psychogenic non-epileptic seizures. Seizure. 2014;23(5):363-366.

149. Kanner AM, Schachter SC, Barry JJ, et al. Depression and epilepsy: epidemiologic and neurobiologic perspectives that may explain their high comorbid occurrence. Epilepsy Behav. 2012;24(2):156-168.

150. Karouni M, Henning O, Larsson PG, Johannessen SI, Johannessen Landmark C. Pharmacological treatment of psychiatric comorbidity in patients with refractory epilepsy. Epilepsy Behav. 2013;29(1): 77-81.

151. Reisinger EL, DiIorio C. Individual, seizure-related, and psychosocial predictors of depressive symptoms among people with epilepsy over six months. Epilepsy Behav. 2009;15(2):196-201.

152. Hecimovic H, Santos JM, Carter J, et al. Depression but not seizure factors or quality of life predicts suicidality in epilepsy. Epilepsy Behav. 2012;24(4):426-429.

153. Sajatovic M, Welter E, Tatsuoka C, Perzynski AT, Einstadter D. Electronic medical record analysis of emergency room visits and hospitalizations in individuals with epilepsy and mental illness comorbidity. Epilepsy Behav. 2015;50:55-60.

154. Crail-Meléndez D, Herrera-Melo A, Martínez-Juárez IE, RamírezBermúdez J. Cognitive-behavioral therapy for depression in patients with temporal lobe epilepsy: a pilot study. Epilepsy Behav. 2012; 23(1):52-56.

155. Kerr M, Gil-Nagel A, Glynn M, Mula M, Thompson R, Zuberi SM. Treatment of behavioral problems in intellectually disabled adult patients with epilepsy. Epilepsia. 2013;54 Suppl 1:34-40.

156. Clancy MJ, Clarke MC, Connor DJ, Cannon M, Cotter DR. The prevalence of psychosis in epilepsy: a systematic review and metaanalysis. BMC Psychiatry. 2014;14:75.

Neuropsychiatric Disease and Treatment

\section{Publish your work in this journal}

Neuropsychiatric Disease and Treatment is an international, peerreviewed journal of clinical therapeutics and pharmacology focusing on concise rapid reporting of clinical or pre-clinical studies on a range of neuropsychiatric and neurological disorders. This journa is indexed on PubMed Central, the 'PsycINFO' database and CAS,
157. Adachi N, Akanuma N, Ito M, Okazaki M, Kato M, Onuma T. Interictal psychotic episodes in epilepsy: duration and associated clinical factors. Epilepsia. 2012;53(6):1088-1094.

158. Adachi N, Kanemoto K, de Toffol B, et al. Basic treatment principles for psychotic disorders in patients with epilepsy. Epilepsia. 2013; 54 Suppl 1:19-33.

159. Mula M. Recognize and manage psychiatric comorbidities in patients with epilepsy. Panminerva Med. 2011;53(4):241-251.

160. Johannessen SI, Landmark CJ. Antiepileptic drug interactions principles and clinical implications. Curr Neuropharmacol. 2010; 8(3):254-267.

161. Caetano D. Use of anticonvulsants as prophylaxis for seizures in patients on clozapine. Australas Psychiatry. 2014;22(1):78-83.

162. Okazaki M, Adachi N, Akanuma N, et al. Do antipsychotic drugs increase seizure frequency in epilepsy patients? Eur Neuropsychopharmacol. 2014;24(11):1738-1744.

163. Levine M, Ruha AM. Overdose of atypical antipsychotics: clinical presentation, mechanisms of toxicity and management. CNS Drugs. 2012;26(7):601-611

164. Verrotti A, Milioni M, Zaccara G. Safety and efficacy of diazepam autoinjector for the management of epilepsy. Expert Rev Neurother. 2015;15(2):127-133.

165. McKee HR, Abou-Khalil B. Outpatient pharmacotherapy and modes of administration for acute repetitive and prolonged seizures. CNS Drugs. 2015;29(1):55-70.

166. Garnett WR, Barr WH, Edinboro LE, Karnes HT, Mesa M, Wannarka GL. Diazepam autoinjector intramuscular delivery system versus diazepam rectal gel: a pharmacokinetic comparison. Epilepsy Res. 2011;93(1):11-16.

167. Lamson MJ, Sitki-Green D, Wannarka GL, Mesa M, Andrews P, Pellock J. Pharmacokinetics of diazepam administered intramuscularly by autoinjector versus rectal gel in healthy subjects: a phase I, randomized, open-label, single-dose, crossover, single-centre study. Clin Drug Investig. 2011;31(8):585-597.

168. Abou-Khalil B, Wheless J, Rogin J, et al. A double-blind, randomized, placebo-controlled trial of a diazepam auto-injector administered by caregivers to patients with epilepsy who require intermittent intervention for acute repetitive seizures. Epilepsia. 2013;54(11):1968-1976.

169. Henney HR 3rd, Sperling MR, Rabinowicz AL, Bream G, Carrazana EJ. Assessment of pharmacokinetics and tolerability of intranasal diazepam relative to rectal gel in healthy adults. Epilepsy Res. 2014;108(7):1204-1211.

170. Thakker A, Shanbag P. A randomized controlled trial of intranasalmidazolam versus intravenous-diazepam for acute childhood seizures. J Neurol. 2013;260(2):470-474.

171. Ivaturi V, Kriel R, Brundage R, Loewen G, Mansbach H, Cloyd J. Bioavailability of intranasal vs rectal diazepam. Epilepsy Res. 2013; 103(2-3):254-261.

172. de Haan GJ, van der Geest P, Doelman G, Bertram E, Edelbroek P. A comparison of midazolam nasal spray and diazepam rectal solution for the residential treatment of seizure exacerbations. Epilepsia. 2010;51(3):478-482.

173. Anderson M. Buccal midazolam for pediatric convulsive seizures: efficacy, safety, and patient acceptability. Patient Prefer Adherence. 2013;7:27-34.

174. Nakken KO, Lossius MI. Buccal midazolam or rectal diazepam for treatment of residential adult patients with serial seizures or status epilepticus. Acta Neurol Scand. 2011;124(2):99-103.

\section{Dovepress}

and is the official journal of The International Neuropsychiatric Association (INA). The manuscript management system is completely online and includes a very quick and fair peer-review system, which is all easy to use. Visit http://www.dovepress.com/testimonials.php to read real quotes from published authors. 